TITLE:

\title{
Phylogeny, hybridization, and life history evolution of Rhinogobius gobies in Japan, inferred from multiple nuclear gene sequences.
}

\author{
AUTHOR(S): \\ Yamasaki, Yo Y; Nishida, Mutsumi; Suzuki, \\ Toshiyuki; Mukai, Takahiko; Watanabe, Katsutoshi
}

\section{CITATION:}

Yamasaki, Yo Y ... [et al]. Phylogeny, hybridization, and life history evolution of Rhinogobius gobies in Japan, inferred from multiple nuclear gene sequences.. Molecular phylogenetics and evolution 2015, 90: 20-33

\section{ISSUE DATE:}

2015-04-27

URL:

http://hdl.handle.net/2433/198127

\section{RIGHT:}

(c) 2015 Elsevier Inc. Licensed under the Creative Commons Attribution-NonCommercial-NoDerivatives 4.0 International http://creativecommons.org/licenses/by-nc-nd/4.0/. NOTICE: this is the author's version of a work that was accepted for publication in 'Molecular Phylogenetics and Evolution'. Changes resulting from the publishing process, such as peer review, editing, corrections, structural formatting, and other quality control mechanisms may not be reflected in this document. Changes may have been made to this work since it was submitted for publication. A definitive version was subsequently published in 'Phylogeny, hybridization, and life history evolution of Rhinogobius gobies in Japan, inferred from multiple nuclear gene sequences', VOL90, 2015, doi:10.1016/j.ympev.2015.04.012.; 許諾条件により本文ファイルは 2016-04-27に公開.; This is not the published version. Please cite only the published version ... 
1 Title: Phylogeny, hybridization, and life history evolution of Rhinogobius gobies in Japan, inferred

2 from multiple nuclear gene sequences

3 Authors: Yo Y. YAMASAKI ${ }^{\mathrm{a}}$, Mutsumi NISHIDA ${ }^{\mathrm{b}, \mathrm{e}}$, Toshiyuki SUZUKI' ${ }^{\mathrm{c}}$, Takahiko MUKAI ${ }^{\mathrm{d}}$,

4 Katsutoshi WATANABE ${ }^{\mathrm{a}}$

5

6 Author's affiliation:

$7 \quad{ }^{\text {a }}$ Graduate School of Science, Kyoto University, Kitashirakawa-oiwake-cho, Sakyo, Kyoto

8 606-8502, Japan

9 e-mail: yo.yamasaki@terra.zool.kyoto-u.ac.jp, watanak@terra.zool.kyoto-u.ac.jp

$10{ }^{\mathrm{b}}$ Atmosphere and Ocean Research Institute, The University of Tokyo, Kashiwa, Chiba 277-8564,

11 Japan

$12{ }^{\mathrm{c}}$ Kawanishi-midoridai Senior High School, 1-8 Kouyoudai, Kawanishi, Hyogo 666-0115, Japan

$13{ }^{\mathrm{d}}$ Faculty of Regional Studies, Gifu University, 1-1 Yanagido, Gifu 501-1193, Japan

14 e Current address: University of the Ryukyus, 1 Senbaru, Nishihara-cho, Okinawa 903-0213,

15 Japan

16

17 Corresponding author:

18 Katsutoshi Watanabe

19 Graduate School of Science, Kyoto University, Kitashirakawa-oiwake-cho, Sakyo, Kyoto

20 606-8502, Japan.

$21 \quad$ Tel.: +81-75-753-4079

22 e-mail: watanak@terra.zool.kyoto-u.ac.jp

23

24 
Abstract

Rhinogobius fishes (Gobiidae) are distributed widely in East and Southeast Asia, and represent the most species-rich group of freshwater gobies with diversified life histories (i.e., amphidromous, fluvial, and lentic). To reveal their phylogenetic relationships and life history evolution patterns, we sequenced six nuclear and three mitochondrial DNA (mtDNA) loci from 18 species, mainly from the mainland of Japan and the Ryukyu Archipelago. Our phylogenetic tree based on nuclear genes resolved three major clades, including several distinct subclades. The mtDNA and nuclear DNA phylogenies showed large discordance, which strongly suggested mitochondrial introgression through large-scale interspecific hybridization in these regions. On the basis of the molecular dating using geological data as calibration points, the hybridization occurred in the early to middle Pleistocene. Reconstruction of the ancestral states of life history traits based on nuclear DNA phylogeny suggests that the evolutionary change from amphidromous to freshwater life, accompanied by egg size change, occurred independently in at least three lineages. One of these lineages showed two life history alterations, i.e., from amphidromous (small egg) to fluvial (large egg) to lentic (small egg). Although more inclusive analysis using species outside Japan should be further conducted, the present results suggest the importance of the life history evolution associated with high adaptability to freshwater environments in the remarkable species diversification in this group. Such life history divergences may have contributed to the development of reproductive isolation.

\section{Keywords}

Rhinogobius, Life history, Introgressive hybridization, Speciation, Nuclear gene, Adaptation to a novel environment 
1. Introduction

Colonization of a novel environment is one of the important factors promoting species diversification (Schluter, 2000; Yoder et al., 2010; Betancur-R. et al., 2012). It is predicted that new selective pressure occurring in novel habitats generates divergent natural selection between the ancestral population and the newly colonized population and promotes adaptation and subsequent ecological speciation (Schluter, 2009; Nosil, 2012). This process is thought to be one of the fundamental mechanisms of adaptive radiation (Schluter, 2000; Losos, 2009).

Migration is a key process for species diversification through colonization of a novel environment (Winker, 2000; McDowall, 2001). Migration promotes gene flow among populations, whereas it also leads to colonization of favorable habitats and consequent ecological divergence (Winker, 2000). Diadromous fishes provide representative cases for such a diversification mechanism along with life history evolution. Diadromous fishes that spawn in rivers are often isolated in freshwaters (i.e., landlocked), which leads to ecological diversification followed by speciation, as suggested in anadromous sticklebacks (McKinnon et al., 2004), amphidromous gobies (Katoh and Nishida, 1994), sculpins (Goto and Andoh, 1990), and galaxias (Waters et al., 2010). These evolutionary processes that accompany the diversification of freshwater-diadromous species, as well as those seen in lakes (e.g., Seehausen, 2006; Bernatchez et al., 2010), are the most remarkable examples of adaptive radiation in fishes (Lee and Bell, 1999; Vega and Wiens, 2012; Betancur-R. et al., 2012, 2015).

The family Gobiidae (Order Gobiifromes; Betancur-R et al., 2013, 2014) is one of the most divergent groups among teleost fishes in terms of the number of species and ecology, and it has interested researchers in the fields of ecology and evolutionary biology (Yamada et al., 2009; Rüber and Agorreta, 2011). The genus Rhinogobius is widely distributed in freshwaters from East to Southeast Asia. It consists of more than 85 species, and it is the largest genus of freshwater gobies (Suzuki et al., 2004; Oijen at al., 2011). The species of this genus are classified into three 
types based on migration-related life history. The amphidromous type is the most general form, in which larval fish flow down to the sea immediately after hatching in the river. This is followed by early feeding and growth at the sea, and then a return the river at the juvenile stage for subsequent growth and reproduction (Mizuno, 2001; Keith and Lord, 2011). Lentic types complete their life cycle in standing freshwaters such as lakes and marshes (Takahashi and Okazaki, 2002; Tsunagawa et al., 2010a, 2010b), whereas fluvial types complete their life cycle in running freshwaters (Mizuno, 1960; Nishijima, 1968; Iwata, 2001a, 2001b). Corresponding to these life history types, there is a large interspecific variation in egg size in Rhinogobius species (Mizuno, 1960; Nishida, 2001; Tamada, 2001; Closs et al., 2013). Amphidromous and lentic species produce small eggs (0.6-0.9 mm in the major axis; Katoh and Nishida, 1994; Tsujimoto, 2008; Takahashi and Okazaki, 2002), whereas fluvial species spawn larger eggs (1.1-2.1 mm; Mizuno, 1960; Katoh and Nishida, 1994). The fluvial species also exhibit egg size variation, i.e., species on the mainland of Japan produce larger eggs (1.4-2.1 mm; Mizuno, 1960) than several species in the Ryukyu Archipelago (1.1-1.5 mm; often called “middle-sized eggs”; Katoh and Nishida, 1994). The egg size variation in Rhinogobius species has been explained as an adaptation to feeding and swimming ability during the larval period (Nishida, 1994, 2001; McDowall, 2007), and to increasing larval survival in rivers, which is a relatively harsh and unproductive environment (Closs et al., 2013). The large number of small eggs produced by amphidromous and lentic species are adaptive to standing waters with abundant small-sized plankton, such as bays, lakes, and marshes, where strong swimming ability is not necessary. On the other hand, fluvial species may need to produce larger eggs and larvae that can persist in running waters, and that utilize large prey items in rivers. Interspecific variation in egg size within fluvial species has been explained by the presence or absence of coexisting predators; larger larvae would be preferred under stronger predation pressure (Nishida, 2001).

These large variations in life history and egg size in Rhinogobius provide a profitable case for 
100

101

102

103

104

105

pursuing adaptive radiation via colonization of novel habitats associated with the ecology of migration (Nishida, 1994, 2001). For the purpose of reconstructing such evolutionary patterns, including those of life histories and the related traits such as egg size, a reliable interspecific phylogeny is essential (Harvey and Pagel, 1991; Schluter, 2000; Losos, 2009). To date, genetic relationships among some Japanese Rhinogobius species have been examined based on allozyme polymorphisms (Masuda et al., 1989; Katoh and Nishida, 1994; Sakai et al., 2000), in which some landlocked species producing large eggs were inferred to have evolved in parallel to different amphidromous species that produce small eggs (Kato and Nishida, 1994; Nishida, 1994, 2001). However, the previous studies targeted only a small set of species and failed to obtain a robust phylogeny; hence, the frequency and generality of the life history changes and evolutionary patterns of related traits have not been well understood. Furthermore, some molecular phylogenetic studies using mitochondrial DNA (mtDNA) sequence data have been conducted for the Rhinogobius species (Aonuma et al., 1998; Mukai et al., 2005). However, mtDNA showed remarkable trans-species polymorphisms, in which the sympatric species tended to form monophyletic clades beyond species boundaries; this strongly suggests interspecific introgressive hybridization (Mukai et al., 2005). In cases involving introgression of organellar genomes via hybridization, phylogenetic information from multiple nuclear genes is necessary to estimate species phylogenetic relationships (Maddison, 1997; Bossu and Near, 2009; Waters et al., 2010; Near et al., 2011).

Given the considerable confusion regarding Rhinogobius taxonomy and the lack of ecological information for large numbers of Rhinogobius species (Suzuki and Chen, 2011), exhaustive analysis, particularly with the inclusion of species outside Japan, is difficult to conduct at present. Therefore, this study focused mainly on the Japanese Rhinogobius species, most of which are endemic to Japan and whose taxonomic and ecological information are relatively well understood. First, we estimated the phylogenetic relationships among all known Japanese species by using 
125

126

multiple nuclear gene sequences. We also estimated their mtDNA-based phylogeny. The objectives of this study were as follows: (1) to reveal the patterns of phylogenetic diversification of Japanese Rhinogobius gobies; (2) to reveal the spatiotemporal patterns of interspecific hybridization causing mitochondrial introgression; (3) to test whether the freshwater species, including fluvial and lentic types, evolved independently from amphidromous species; and (4) to reveal the relationships between life history and egg size evolution.

\section{Materials and Methods}

\subsection{Sampling}

A total of 18 species of Rhinogobius are known from Japanese waters, 15 of which are endemic to Japan (Suzuki and Chen, 2011; Akihito et al. 2013, but see below; Fig. S1; Table S1). Although their species status has been evidenced by morphological, ecological, and genetic studies, scientific names of more than half of the species have yet to be determined or provided mainly because of their morphological similarity, insufficient taxonomic description, and poor condition of type specimens (Mizuno, 2001; Suzuki et al., 2011). Specific codes consisting of two alphabet characters have been commonly used for such species (e.g., BW, BB, DL; Mizuno, 2001; Akihito et al., 2002, 2013) and are also used in this paper. We basically followed the classification of Akihito et al. (2013), which includes 17 Japanese species. However, since one (or more) species classified into Rhinogobius sp. OR (sensu Akihito et al., 2002) was not included in Akihito et al. (2013), we tentatively use the name Rhinogobius sp. OR for the unclassified species.

A total of 96 specimens of 18 Japanese species were collected from the mainland of Japan, the Ryukyu Archipelago, and the Bonin Islands from 2001 to 2013 (Tables 1 and S2; Fig. 1). Specimens of wide-ranging species were sampled from two to eight geographically distant locations, if possible. These specimens, along with three specimens of the three continental species ( $R$. giurinus, $R$. leavelli, and $R$. virgigena), were used in the analyses. 
We took photographs of live specimens whenever possible and identified the species according to references (Akihito et al., 2002, 2013; Suzuki et al., 2004; Chen and Kottelat, 2005). Specimens were anesthetized using 2-phenoxyethanol, and their right pectoral fin or muscle tissue was preserved in $100 \%$ ethanol for DNA extraction. The specimens were fixed in $10 \%$ formalin, transferred to 70\% ethanol, and deposited in the National Museum of Nature and Science, Tokyo, as voucher specimens (NSMT-P 65160, 65165, 120783-120861).

2.2. DNA extraction, PCR, and sequencing

Total genomic DNA was extracted using a Genomic DNA Purification Kit (Promega, Madison, Wisconsin, USA). PCR amplification targeted three regions of mtDNA [cytochrome c oxidase subunits 1 (CO1), NADH dehydrogenase subunits 5 (ND5), and cytochrome b (cytb); total of $2781 \mathrm{bp}$ ] and six regions of nuclear DNA [myosin heavy polypeptide 6 (myh6), a novel protein similar to vertebrate ryanodine receptor 3 (RYR3), hypothetical protein LOC564097 (Ptr), super conserved receptor expressed in brain 2 (sreb2), recombinase-activating proteins 2 (RAG2), early growth response gene family 3 (EGR3); total of $4755 \mathrm{bp}$ ]. The primer sets and annealing temperature settings followed those in previous studies (see Table S3). New primer sets for Ptr and RAG2 were designed for a part of specimens based on the sequences determined for Rhinogobius specimens using Primer3 (Rozen and Skaletsky, 2000). mM dNTP mix, $1.5 \mu \mathrm{l}$ Ex-Taq buffer, $1.5 \mu \mathrm{l}$ of each $5 \mu \mathrm{M}$ primer, $0.3 \mu \mathrm{l}$ Ex-Taq DNA polymerase

170 (Takara, Shiga, Japan), and $1 \mu \mathrm{l}$ (ca. 10-100 ng) of DNA template. We also used KOD FX or

171 KOD Plus Neo (Toyobo, Osaka, Japan) for specimens in which the amplification was difficult.

172 The PCR using KOD FX was performed in a 15- $\mu$ l volume containing $2.4 \mu 1$ ultrapure water, $3 \mu 1$ $1732.0 \mathrm{mM}$ dNTP mix, $7.5 \mu \mathrm{l}$ buffer, $0.9 \mu \mathrm{l}$ of each $5 \mu \mathrm{M}$ primer, $0.3 \mu \mathrm{l}$ KOD FX DNA polymerase, and $1 \mu \mathrm{l}$ of DNA template. The PCR using KOD Plus Neo was performed in a 15- $\mu 1$ volume 
175 containing $8.0 \mu \mathrm{l}$ ultrapure water, $1.5 \mu \mathrm{l} 2.0 \mathrm{mM}$ dNTP mix, $1.5 \mu \mathrm{l}$ buffer, $0.9 \mu \mathrm{l} 25 \mathrm{mM} \mathrm{MgCl}_{2}$,

$176 \quad 0.9 \mu \mathrm{l}$ of each $5 \mu \mathrm{M}$ primer, $0.3 \mu \mathrm{K}$ KOD Plus Neo DNA polymerase, and $1 \mu \mathrm{l}$ of DNA template.

177 The settings for PCR using Ex-Taq consisted of the first step (denature, $94{ }^{\circ} \mathrm{C}, 2 \mathrm{~min}$ ), 35 cycles

178 of the second step (denature, $94^{\circ} \mathrm{C}, 30 \mathrm{~s}$; annealing, $48-62{ }^{\circ} \mathrm{C}, 30 \mathrm{~s}$; extension, $72{ }^{\circ} \mathrm{C}, 1 \mathrm{~min}$ ), and

179 the last step (extension, $68^{\circ} \mathrm{C}, 7 \mathrm{~min}$ ); and those for PCR using KOD FX or KOD Plus Neo

180 consisted of the first step (denature, $94^{\circ} \mathrm{C}, 2 \mathrm{~min}$ ), 35 cycles of the second step (denature, $98^{\circ} \mathrm{C}$,

$18110 \mathrm{~s}$; annealing, $55-62{ }^{\circ} \mathrm{C}, 30 \mathrm{~s}$; extension, $68^{\circ} \mathrm{C}, 30-40 \mathrm{~s}$ ), and the last step (extension, $68^{\circ} \mathrm{C}, 7$

182 min). Nested PCR was performed using two primer pairs described by Li et al. (2007) in some

183 samples; PCR products were diluted 20-100 times with water, and PCR was performed again

184 using these diluted PCR products as templates.

185 The PCR products were purified using ExoSAP-IT (USB Corporation, Cleveland, OH, USA)

186 or Illustra ExoStar (GE Healthcare, Little Chalfont, Buckinghamshire, UK) at $37^{\circ} \mathrm{C}$. They were

187 sequenced using an automated DNA sequencer (ABI 3130xl, Applied Biosystems, Foster City, CA,

188 USA) with the above amplification primers and using the BigDye Terminator Cycle Sequencing

189 FS Ready Reaction Kit ver. 3.1 (Applied Biosystems).

190 Nucleotide sequences were edited in MEGA5 (Tamura et al., 2011) or MacClade 4.08a

191 (Maddison and Maddison, 2000). The DNA sequences were aligned using ClustalW (Larkin et al., 192 2007) or manually. Heterozygous sites within individual specimens were rare (0-1.1\% for genes);

193 these were coded as IUPAC degenerate nucleotide symbols and directly used in the analyses. The 194 obtained sequences were deposited in DDBJ/GenBank/EMBL (accession nos. AB988263195 AB988988).

2.3. Inference of molecular phylogeny

Gene trees were constructed using maximum likelihood (ML) and Bayesian methods. We chose

199 Rhinogobius giurinus as the outgroup because it is the most distant species within the genus 
200 (Masuda et al., 1989; Mukai et al., 2005). Maximum likelihood analyses were carried out using

201 RAxML-7.2.6 (Stamatakis, 2006). We analyzed three types of data sets, i.e., concatenated data of

202 the three mtDNA regions, six sets of each nuclear gene, and concatenated data of the six nuclear

203 genes. Model selections based on Akaike information criterion (AIC) and optimal partition setting

204 analysis were performed using PartitionFinder v1.0.0 (Lanfear et al., 2012) (Table S4). We treated

205 each gene as a single locus and partitioned it by codon position. The partition scheme was

206 searched using the "greedy” algorithm. The evolutionary model was selected from GTR, GTR+I,

207 GTR+G, or GTR+I+G models based on the AIC. The credibility of clades was evaluated by 1000

208 bootstrap replicates. Bayesian analyses were implemented using MrBayes 3.2.1 (Ronquist and

209 Huelsenbeck, 2003) for two data sets (concatenated three mtDNA regions and concatenated six

210 nuclear genes). Model selection based on the Bayesian information criterion (BIC) and optimal

211 partition setting analysis were performed using PartitionFinder with the "greedy" algorithm. We

212 treated each gene as a single locus and partitioned it by codon position. In MrBayes, the analysis

213 was run for 20 and 50 million generations (for mtDNA and nuclear DNA, respectively), with two

214 independent runs of four Markov chain Monte Carlo (MCMC) chains and sampling every 100

215 generations. The trace files were checked in Tracer 1.5 (Rambaut et al., 2013) to ensure that the

216 chains had reached convergence and the first 25\% of trees were discarded as burn-in. Trees were

217 visualized using FigTree v1.3.1 (Rambaut, 2009).

218 When a maximum likelihood tree or Bayesian tree topology did not support the monophyly of

219 some morphological species, we conducted a statistical test of monophyly of the species as

220 described below. First, we estimated the maximum likelihood tree under monophyletic constraints

221 of the species by RAxML. Second, we conducted the approximate unbiased (AU) tests

222 (Shimodaira, 2002) in CONSEL (Shimodaira and Hasegawa, 2001) for the two trees that were

223 constructed under constraints or no constraints (i.e., maximum likelihood tree) and confirmed

224 whether the monophyly of the species was statistically rejected or not. 


\subsection{Estimation of divergence time}

We estimated the divergence time from concatenated data of mtDNA regions and nuclear genes, independently. Because to date, no fossil records are available that could be used to construct the

tree for Rhinogobius and its relatives, we used the following two geographic events and previously

estimated molecular evolutionary rates for divergence time calibration. First, the Bonin Islands are

231 oceanic islands that have never been connected to continents. They were formed 1.8 million years ago (Mya) or later, and it is assumed that their endemic fauna was formed 0.9-1.8 Mya (Kaizuka, 1977; Imaizumi and Tamura, 1984; Chiba, 2002). The time of the most recent common ancestors

(tMRCA) of $R$. ogasawaraensis (endemic species to the Bonin Islands) and its sister species, or its clade was constrained following a normal prior distribution within the limit of 0-2.0 million years $(\mathrm{Myr})($ mean $=1.8$, standard deviation $(\mathrm{SD})=0.4$; calibration $1, \mathrm{CA} 1)$. Since it is possible that interspecific hybridization occurred after this divergence (see Discussion), we did not use this constraint in the mtDNA-based phylogenetic tree. Secondly, we used the opening time of the Tokara Gap, which divided the Japanese Archipelago and the Ryukyu Archipelago (1.55 \pm 0.154

Mya; Osozawa et al., 2012). Migration of amphidromous Rhinogobius species between the

mainland and Ryukyu Archipelago just after the opening of the gap was probably not restricted because their larvae can disperse through the coastal areas. With further extension of the gap, their possible migration across the gap gradually decreased; finally, the isolation of populations at either side of the gap was complete. Therefore, we used the opening time of the Tokara Gap as the upper

245 limit of the divergence time between mutually monophyletic groups distributed in the mainland

246 and in the Ryukyu Archipelago. The tMRCA of the mutually monophyletic groups was

247 constrained following a normal prior distribution within the limit of 0-1.7 Myr (mean = 1.55, SD

$248=0.4$; calibration 2, CA2). Since the mtDNA phylogeny revealed the existence of mainland and

249 Ryukyu groups beyond species boundaries (see Results), we applied CA2 to their tMRCA. On the 
other hand, in the nuclear DNA analysis, we used this constraint only for clear intraspecific

divergence because a previous study suggested that another older geographic event could have

caused a similar vicariance pattern between mainland and Ryukyu species in some gobiid groups

(Mukai, 2010). Finally, we used the molecular evolutionary rate of 3.0\%/Myr (pairwise) (95\%

highest posterior density (HPD), 0.7-4.8\%/Myr) for cytb, which was estimated for the genus

Gymnogobius (Tabata and Watanabe 2013), phylogenetically relatively close to Rhinogobius

(Agorreta et al., 2013). We assumed that the evolutionary rate of cytb followed a lognormal prior

distribution ranging from 0.0 to $10^{100}$ per Mya (initial value $=0.015$, mean $=0.015, \mathrm{SD}=0.7$,

offset $=0.0$, mean in real space $=$ yes $)$.

We used BEAST v1.7.5 (Drummond et al., 2012) to estimate the divergence time of trees

inferred using mtDNA and nuclear genes, respectively. Originally, we attempted to construct a

species tree by using *BEAST (Heled and Drummond, 2010) for nuclear genes using several prior

settings. However, the parameters did not converge and we abandoned this analysis. Later, we

attempted to conduct the phylogenetic analysis with different evolutionary models for respective

nuclear genes, but the parameters did not converge well either. Although the reason for this was not clear, it might be possible that low sequence variation and introgression in a part of the loci might influence the analyses. Finally, we concatenated sequences from the six nuclear genes and estimated a dated nuclear gene tree. In order to date the tree, we adopted the random local clock model, which assumes one or more independent rates on different branches (Drummond and

269 Suchard, 2010). We did not specify partition by codon position, because the parameters did not converge in mtDNA or nuclear DNA data when partitioned. We used jModelTest v2.1.3 (Darriba

271 et al., 2012) to select the evolutionary model without partitioning and selected the best model based on BIC. We selected the speciation tree prior (Yule process; Yule, 1925; Gernhard, 2008) and estimated a starting tree using the UPGMA method. We conducted MCMC analysis four times independently. For each MCMC, we performed a run of 50 and 100 million generations (for 
mtDNA and nuclear genes, respectively), sampling every 1000th generation. The first $10 \%$ of the trees were discarded as burn-in for each run. We assessed whether parameter values for individual runs had reached equilibrium and convergence by visually assessing their trace plots in Tracer 1.5. Individual chains were combined using the LogCombiner v1.7.5. Finally, we analyzed combined runs using Tree Annotator v1.7.5.

\subsection{Reconstruction of ancestral states}

We conducted ancestral state reconstruction for life history and egg size traits under the multiple state speciation and extinction (MuSSE) model (FitzJohn, 2012). If speciation, extinction, and

character transition rates are different associated with traits, assuming equal rates for these parameters under ML framework will be a major violation of the ancestral state reconstruction (Maddison, 2006; Goldberg and Igić, 2008; Pyron and Burbrink, 2014). The MuSSE model is one of the models accounting for such state-dependent diversification and a generalized version of binary state speciation and extinction (BiSSE) model (Maddison et al., 2007) to allow the use of multistate characters. The MuSSE analysis was applied to the smallest monophyletic group including all Japanese species, for which taxon sampling was dense. We chose one sample for every species randomly and excluded the other samples from the nuclear DNA tree inferred by BEAST using the 'ape’ package (Paradis et al., 2004) in R (R Development Core Team, 2014).

293 Exceptionally, two samples were used for R. flumineus and Rhinogobius sp. OR because they were 294 suggested to be non-monophyletic. We then conducted a model comparison between the full MuSSE model and 11 parameter-constrained sub-models. We selected the best model using AIC scores. Finally, we conducted an ancestral state reconstruction under the selected model in the ML framework. The model selection and ancestral state reconstruction under the MuSSE model were conducted using the R package 'diversitree’ v 0.9-7 (FitzJohn, 2012). The data for life history and 299 egg size of each species were obtained from previous studies (see Tables 1, S1). 
3. Results

302

3.1. Phylogeny and divergence time estimates based on mtDNA sequences

303

The maximum likelihood and Bayesian analyses based on three mtDNA regions revealed six

304

clades in the Japanese Rhinogobius species (Fig. 2): M-1 (R. ogasawaraensis, bootstrap

305

probability inferred by RAxML [BP] 100\%, posterior probability inferred by MrBayes [PPM]

100\%, posterior probability inferred by BEAST [PPB] 1.0); M-2 (Rhinogobius sp. BW, BP 100\%,

PPM 1.0, PPB 1.0); M-3 (Rhinogobius sp. TO, BP 100\%, PPM 1.0, PPB 1.0); M-4 (R. flumineus,

BP 100\%, PPM 1.0, PPB 1.0); M-5 (R. nagoyae collected from the mainland of Japan; BP 100\%,

PPM 1.0, PPB 1.0); M-6 (other samples collected from the mainland of Japan; BP 100\%, PPM 1.0,

PPB 1.0); and M-7 (other samples collected from the Ryukyu Archipelago; BP 81\%, PPM 0.99,

PPB 0.99). Rhinogobius nagoyae and $R$. brunneus, which are distributed both on the mainland of

M-6, Rhinogobius sp. OR and R. fluviatilis were not monophyletic (AU test, Rhinogobius sp. OR, $\mathrm{p}<0.001 ;$ R. fluviatilis, $\mathrm{p}<0.001)$. In the clade M-7, R. brunneus and Rhinogobius sp. BB were also not monophyletic (AU test, $R$. brunneus, $\mathrm{p}<0.001$; $R$. sp. BB, $\mathrm{p}<0.001$ ).

318 collected from the mainland of Japan) and M-7 (collected from the Ryukyu Archipelago)

319 haplotypes. The tMRCA of these was estimated at 1.17 Myr (95\% HPD, 0.62-1.70 Myr in Table

320 2). The tMRCA of all the Japanese Rhinogobius species was estimated at1.59 Myr (0.73-2.39

$321 \mathrm{Myr}$ ), and the tMRCAs of M-5+M-6 and M-7 were 1.02 Myr (0.49-1.52 Myr) and 0.97 Myr 322 (0.47-1.44 Myr), respectively. 
The variable sites and parsimony informative sites of the nuclear genes for Rhinogobius fishes,

excluding $R$. giurinus, were 2.5\% (EGR3)-9.9\% (RAG2), and 1.3\% (sreb2)-5.7\% (RAG2),

respectively. Although the resolution and statistical support of the phylogenetic trees based on

each nuclear DNA data set were low (Figure S2), they were much improved in the ML and

Bayesian trees based on the concatenated dataset (Fig. 3). The descriptions and analyses hereafter are based on ML and Bayesian trees inferred from the six nuclear genes.

In contrast to the result of mtDNA analyses, most of the respective species were resolved as

monophyletic in the nuclear gene trees. The Japanese species were monophyletic in the current dataset, and they were divided into three clades with strong or moderate statistical supports (Fig.

3): clade N-1 (R. flumineus and $R$. sp. TO; BP 95\%, PPM 1.0, PPB 1.0); N-2 (R. nagoyae and $R$. sp. CO; BP 68\%, PPM 0.99, PPB 0.95); and N-3 (the remaining 13 species; BP 78\%, PPM 1.0, PPB 1.0). The N-3 clade was further divided into three subclades: N-3-1 (R. brunneus and

Rhinogobius sp. YB; BP 65\%, PPM 0.96, PPB 0.99); N-3-2 (R. fluviatilis, $R$. ogasawaraensis, and Rhinogobius sp. DL; BP 83\%, PPM 1.0, PPB 1.0); and N-3-3 (Rhinogobius sp. MO, Rhinogobius

sp. BB, Rhinogobius sp. OR, Rhinogobius sp. BW, Rhinogobius sp. BF, Rhinogobius sp. OM,

Rhinogobius sp. KZ, and R. kurodai; BP 100\%, PPM 1.0, PPB 1.0). None of the analyses resolved the relationships among $\mathrm{N}-1, \mathrm{~N}-2$, and $\mathrm{N}-3$ clades.

In the N-1 clade, Rhinogobius sp. TO formed a monophyletic group with a part of $R$. flumineus samples (BP 57\%, PPM 0.93, PPB 0.90). Although statistical support was weak, $R$. brunneus and Rhinogobius sp. YB were each polyphyletic in N-3-1 (AU test, Rhinogobius sp. YB, p = 0.42; $R$. brunneus, $\mathrm{p}=0.335)$. In N-3-2 clade, $R$. fluviatilis and $R$. ogasawaraensis constituted a sister group with Rhinogobius sp. DL (BP 83\%, PPM 1.0, PPB 1.0). In N-3-3, Rhinogobius sp. MO and Rhinogobius sp. BB formed a weakly supported monophyletic group in the ML tree (BP 52\%, PPB 0.54; not supported by MrBayes analysis). The resolution of the relationships among other specimens, including Rhinogobius sp. OR, Rhinogobius sp. BW, Rhinogobius sp. BF, Rhinogobius 
sp. OM, Rhinogobius sp. KZ, and R. kurodai was low. Rhinogobius sp. BW, a species endemic to Lake Biwa, the largest lake in Japan, formed a monophyletic group with Rhinogobius sp. BF, distributed in western area of the mainland of Japan, and Rhinogobius sp. OM, distributed in the coastal area and rivers flowing into Lake Biwa, but the statistical support was weak (BP 70\%, PPM 0.53, PPB 0.64).

We applied the calibration point CA1 ( $<2 \mathrm{Myr}$ ) for the tMRCA of $R$. fluviatilis (distributed widely in the mainland of Japan) and R. ogasawaraensis (endemic to the Bonin Islands) and CA2 ( $<1.7 \mathrm{Myr}$ ) for the tMRCA of $R$. nagoyae on the mainland of Japan and the Ryukyu Archipelago (Fig. 4). As a result of these calibration points, the divergence time of $R$. ogasawaraensis and $R$. fluviatilis was estimated at 1.55 Myr (95\% HPD, 1.05-2.00 Myr), and that of $R$. nagoyae on the mainland of Japan and the Ryukyu Archipelago was estimated at 1.14 Myr (0.68-1.69 Myr). The tMRCAs among the species that are geographically isolated from each other whose distributions were geographically separated were estimated as follows (Table 2): tMRCA of N-3-2 (R. fluviatilis [the mainland], R. ogasawaraensis [Bonin Islands], and Rhinogobius sp. DL [Ryukyu Archipelago]) was 1.78 Myr (1.03-2.53 Myr); tMRCA of a part of N-3-3 (Rhinogobius sp. OR + Rhinogobius sp. KZ + Rhinogobius kurodai [the mainland] and Rhinogobius sp. MO + Rhinogobius sp. BB [Ryukyu Archipelago]) was 1.20 Myr (0.59-1.89 Myr); and tMRCA of Rhinogobius sp. BW (Lake Biwa) + Rhinogobius sp. BF (western area of the mainland of Japan) + Rhinogobius sp. OM was 1.10 Myr (0.49-1.77 Myr). The tMRCA of the Japanese Rhinogobius species, except for $R$. giurinus, was estimated at about 4.48 Myr (2.38-6.66 Myr).

\subsection{Ancestral state reconstruction}

The best-fit model among the MuSSE sub-models was the simplest model for both life history and egg size, i.e., speciation, extinction, and transition rates were independent to state (Table S6). In the Rhinogobius species of Japan, the life history and egg size transformations were estimated 
to have occurred at least five and four times, respectively, although the proportional likelihood values were not very high for parts of the ancestral states (59.6-99.9\%; Fig. 4a). The estimated egg size transformations always occurred together with life history transformation. The evolutionary change from amphidromous to fluvial life, accompanied by an increase in egg size, was estimated to have occurred in at least three independent lineages ( $R$. flumineus, Rhinogobius sp. BB, and Rhinogobius sp. YB). The evolutionary change from amphidromous to lentic life was estimated to have occurred in one lineage (Rhinogobius sp. BW and Rhinogobius sp. BF). There was no clear change in egg size in this lineage (Tables 1, S1). In the R. flumineus and Rhinogobius sp. TO lineage, it was inferred that the lentic life most likely evolved from the fluvial life of $R$. flumineus, accompanied by a decrease in egg size.

\section{Discussion}

4.1 Phylogenetic relationships of Japanese Rhinogobius fishes and their biogeography Our analysis using multiple nuclear gene data from all known Japanese Rhinogobius species revealed the existence of three major clades and resolved the overall relationships among the species. Previously, morphological studies have not been conducted to infer the phylogenetic relationships of Rhinogobius fishes because of their generally high level of morphological similarity. Although phylogenetic hypotheses for selected species from the mainland of Japan have been inferred from the allozyme data, consistent and reliable results have not been obtained (Masuda et al., 1989; Sakai at al., 2000). The present study is the first to examine the phylogenetic relationships of Rhinogobius using dense taxonomic sampling, although it was mostly restricted to Japanese species.

The inferred phylogenetic relationships suggest several biogeographic scenarios that explain the divergence among the species. Among the freshwater species of Rhinogobius, the close relationship between $R$. flumineus (fluvial) and Rhinogobius sp. TO (lentic) was revealed in this 
400

401

402

403

404

405

study. Although statistical support was not strong, the latter being derived from a clade within the former in the early to middle Pleistocene (1.43 Mya; 95\% HPD, 0.48-2.44 Mya). Rhinogobius flumineus is distributed widely in western Japan, including the Ise Bay area, in which Rhinogobius sp. TO has a restricted distribution (Suzuki and Sakamoto, 2005; Fig. 4b). The latter species occurs in marsh habitats of hilly areas with rich spring waters (Suzuki and Mukai, 2010). This area has been rich in lentic environments since the Pliocene; e.g., a large wetland area known as the Paleo-Lake Tokai existed from the Pliocene to the middle Pleistocene (Yoshida, 1990; Makinouchi, 2001). The distribution, habitat, and speciation of Rhinogobius sp. TO may be associated with such past lentic environments.

Other freshwater species, Rhinogobius sp. BF, Rhinogobius sp. BW, and Rhinogobius sp. OM, formed a monophyletic clade, but with weak statistical support. They are distributed in marshes and ponds around the Seto Inland Sea, the pelagic zone of Lake Biwa, and coastal areas and rivers flowing into Lake Biwa (Fig. 4c). Their common ancestor was estimated to have diverged from a part of Rhinogobius sp. OR, which is amphidromous and distributed widely on the mainland of Japan. The common ancestor probably adapted to freshwater environments around the Seto Inland Sea area, in which there existed a large-scale freshwater system (known as the Second Seto Inland Lake/River system), including the Paleo-Lake Biwa at the eastern edge (Yokoyama and Nakagawa, 1991). The estimated tMRCA of Rhinogobius sp. BW and part of Rhinogobius sp. BF (0.90 Myr; 0.35-1.51 Myr; Table 2) is roughly congruent with the time when the large, deep offshore environment of Lake Biwa started to develop (0.4 Mya; Yokoyama, 1984; Meyers et al., 1993; Kawabe, 1994). This suggests that Rhinogobius sp. BW has derived from the ancestral lentic form with and adapted to the pelagic environment of Lake Biwa.

The inferred phylogenetic relationships and geographic distributions suggest the patterns of allopatric speciation in amphidromous species. Rhinogobius ogasawaraensis, endemic to the Bonin Islands, oceanic islands $1000 \mathrm{~km}$ south of the mainland of Japan (Suzuki et al., 2011), was 
estimated to be the sister species of $R$. fluviatilis, which is widely distributed on the mainland of Japan (Fig. 4d). Prior to the present study, $R$. ogasawaraensis was considered closely related to $R$. brunneus in body color characteristics (Suzuki, 1992). However, our results suggest that $R$. ogasawaraensis was established by colonization of the common ancestor with $R$. fluviatilis from the mainland of Japan after the separation from Rhinogobius sp. DL, which is distributed in the Ryukyu Archipelago. Although amphidromous species may extend their geographic range through coastal or marine habitats (McDowall, 2001), juveniles of amphidromous Rhinogobius species are restricted to the coastal zone (Oshiro and Nishijima, 1978; Kondo et al., 2013) and probably do not migrate across the open ocean. Therefore, the dispersal from the mainland to the Bonin Islands would be an exceptional event.

Marine environments at smaller spatial scales also affect gene flow and probably the allopatric speciation of Rhinogobius species. The opening of the Tokara Gap, which isolated the terrestrial biota between the Japanese and Ryukyu archipelagos (Ota, 1998), probably also caused divergence in some species groups of the amphidromous Rhinogobius. There were three sets of mutually monophyletic lineages distributed in the mainland of Japan (+ the Bonin Islands) and the Ryukyu Archipelago; i.e., $R$. nagoyae (the mainland) vs. $R$. nagoyae (Ryukyu) in N-2; $R$.

fluviatilis (the mainland) + R. ogasawaraensis (Bonin) vs. Rhinogobius sp. DL (Ryukyu) in N-3-2; Rhinogobius sp. OR + Rhinogobius sp. KZ + R. kurodai (the mainland) vs. Rhinogobius sp. MO + Rhinogobius sp. BB (Ryukyu) in N-3-3. The estimated divergence time of each pair was 1.14 (95\% HPD, 0.68-1.69; this used as a calibration point), 1.78 (95\% HPD, 1.03-2.53), and 1.20 (95\% HPD, 0.59-1.89) Myr, respectively (Table 2), showing similar values among the pairs. This roughly supports the hypothesis that the opening of the Tokara Gap caused the divergence in these groups. The distribution of Rhinogobius sp. DL extends to north of the Tokara Gap. This might have resulted from secondary dispersal and should be examined based on detailed population structures in future studies. 
The opening of the Tokara Gap similarly explains the divergence between the mainland of

451 Japan and Ryukyu subspecies of the osmeriform Plecoglossus altivelis (ca. 1 Myr divergence;

452 Nishida, 1985, 1986), which is the representative of amphidromous species distributed widely in

453 East Asia, similarly to Rhinogobius. In contrast to the above three Rhinogobius groups and other

454 taxa such as $P$. altivelis, $R$. brunneus did not show any significant differentiation between the

455 Japanese and Ryukyu archipelagos. The different dispersal abilities of their larvae may explain the 456 presence or absence and the extent of the genetic differentiation among the species pairs.

4.2 The history of hybridization inferred from mtDNA introgression

The inconsistency between our mtDNA and nuclear DNA inferred phylogenies suggests a

large-scale introgressive hybridization involving multiple Rhinogobius species within Japan. In

the mtDNA phylogeny, the mainland and Ryukyu populations of two widely distributed species ( $R$.

nagoyae and $R$. brunneus) formed a group with other species in those regions. Overall, specimens

of nine species from the mainland formed a monophyletic group (M-5 + M-6), although statistical

support was not strong, and those of six species from the Ryukyu Archipelago formed a

monophyletic group (M-7). However, such polyphyletic relationships were statistically rejected by

the nuclear DNA data; morphologically defined species basically formed a monophyletic group.

This pattern of geographical sorting of the mtDNA lineages is explained by interspecific

because the latter is expected to cause more random distribution of mtDNA haplotypes.

The mtDNA phylogeny, along with the nuclear gene phylogeny and divergence time

estimations, provides information on historical patterns of hybridization in Rhinogobius. First,

473 (except for $R$. giurinus) in the mtDNA phylogeny; nevertheless, $R$. ogasawaraensis was included 
introgression involving almost all species in both Japanese and Ryukyu archipelagos started with a common haplotype (or close haplotypes) after the divergence of $R$. ogasawaraensis. Second, the mtDNA and nuclear DNA analyses gave similar estimation of the divergence time of $R$. ogasawaraensis (1.59 and 1.55 Myr, respectively) although different calibration sets were used (Table 2). This agreement probably validates the estimation that the large-scale introgression occurred around that time (the early to middle Pleistocene). Third, even within the mainland of Japan or the Ryukyu region, mtDNAs resolved a part of species polyphyletic (e.g., the mainland $R$. fluviatilis and Ryukyu Rhinogobius sp. BB). This also supports the limited but ubiquitous hybridization in the Rhinogobius fishes, although incomplete lineage sorting in mtDNA is an alternative explanation in this scale. Fourth, it should be noted that freshwater species, such as $R$. flumineus, Rhinogobius sp. TO, Rhinogobius sp. BW (the mainland), and a part of Rhinogobius sp. BB (Ryukyu), branched out earlier and have retained their independent lineages in the mtDNA phylogeny. This tendency suggests that the reproductive isolation between amphidromous and freshwater species is stronger than that between amphidromous species and has prohibited the freshwater species from hybridizing with other species.

What type of historical process has constructed the above patterns? Interspecific hybridization often occurs in the conditions of enforced syntopic occurrence, which is caused by, for instance, reduction of habitats and secondary contact of populations following disappearance of geographic or ecological barriers (Seehausen, 2004; Toews and Brelsford, 2012). Although the Rhinogobius species show similar reproductive habits that include oviposition under a stone and male parental care for the eggs, reproductive isolation among sympatric species is achieved by micro- or mesoscale differences of spawning habitat in the river course (Mizuno, 1982; Tamada, 2000; Hirashima and Tachihara, 2006), assortative mating based on nuptial coloration and courtship behavior (Mizuno, 1987), or both. However, some conditions causing disturbance of such reproductive isolation would have occurred since the early to middle Pleistocene, in which the 
500 large part of Japanese Rhinogobius would have experienced large-scale hybridization. Freshwater

501 habitat reduction by the rise in sea level with global climate fluctuations might be one such

502 potential situation causing the overlap of spawning habitats among species. Mukai et al. (2012)

503 reported that introgressive hybridization has occurred contemporarily among some freshwater

504 Rhinogobius species following artificial transplantation. This example demonstrates that

505 environmental distribution or changes can easily disturb reproductive isolation among

506 Rhinogobius fishes. Furthermore, if some types of mtDNA were favored by natural selection,

507 large-scale introgression of the particular mtDNA would rapidly progress through interspecific

508 hybridization (Ballard and Whitlock, 2004). The Rhinogobius fishes may provide a model system

509 to study the mechanisms of maintenance and decay of reproductive isolation, such as the Lake

510 Victoria cichlids that suffered a collapse of assortative mating based on visual sense with the

511 increase of turbidity (Seehausen et al., 1997). This group may also be useful as a model system for

512 studying mitochondrial introgression and replacement through interspecific hybridization (Mukai

513 and Takahashi, 2010).

\subsection{Life history and egg size evolution and speciation}

We successfully reconstructed the patterns of life history and egg size evolution of Rhinogobius

species in Japan. Because of our taxon sampling bias toward Japanese species, careful

consideration is needed for reconstruction and explanation of evolutionary patterns of ecological

traits. However, since all non-amphidromous and some amphidromous species used in this study

transformation based on our phylogeny should provide meaningful insights into ecological and species diversification in Rhinogobius fishes. 
525

526

527

528

529

530

531

532

533

534

535

536

537

538

539

540

541

542

543

transformations, i.e., from an amphidromous to a fluvial type, from an amphidromous to a lentic type, and from a fluvial to a lentic type. Although statistical support of the ancestral reconstruction associated with the last transformation was not very strong, the pattern is supported by the geographical distribution of the relevant species (see below).

The first pattern, from amphidromous to fluvial, is inferred to have occurred independently in the $R$. flumineus, Rhinogobius sp. YB, and Rhinogobius sp. BB lineages, when they diverged from their ancestors. In all three fluvial species, their egg size became larger than that of the amphidromous species. The reconstruction remains ambiguous for $R$. flumineus due to its basal phylogenetic position in Japanese species and the presence of several unexamined fluvial/large egg species in the continent (Chen et al., 2008). On the other hand, the other two fluvial species (Rhinogobius sp. YB and Rhinogobius sp. BB) occurring in the Ryukyu Archipelago most likely originated directly from $R$. brunneus and Rhinogobius sp. MO, respectively, based on their phylogenetic relationships, recent divergence times, and restricted geographic distribution of the fluvial species. This means that convergent evolution of the increase in egg size occurred at least in these two lineages. This conclusion agrees with the inference from previous studies based on allozyme polymorphism (Kato and Nishida, 1994; Nishida, 1994). Based on the restricted occurrence of Rhinogobius sp. YB in the upper reaches of waterfalls, Nishida (1994, 2001) and Kano et al. (2012) suggested that this species evolved through parallel evolution from the amphidromous ancestor ( $R$. brunneus) as a result of population isolation following the formation of waterfalls. On the other hand, since Rhinogobius sp. BB is usually found in rivers without waterfalls, Kondo et al. (2013) inferred that this species derived from the ancestral Rhinogobius sp. MO population that invaded the upper reaches of rivers when the sea level decreased and rivers increased in length. To test these hypotheses for evolutionary processes of the fluvial species, further study from multiple aspects, including population genetics with highly sensitive multilocus markers, is needed. 
The second pattern of life history transformation, from amphidromous (Rhinogobius sp. OR or OM) to lentic (Rhinogobius sp. BF + Rhinogobius sp. BW), involved a slight decrease in egg size (Takahashi and Okazaki, 2002). The difference in their egg size is not as large as that between fluvial (large egg) and amphidromous (small egg) species (Table S1; Takahashi and Okazaki, 554 2002). Since larvae of both the amphidromous and lentic species grow in a plankton-rich 555 environment (i.e., the sea near a river mouth and lakes or ponds), such similar feeding environments may not cause remarkable differences in the adaptive sizes of their hatched larvae and eggs in relation to feeding efficiency. However, the lentic species are possibly released from the lower limit of egg size needed for enduring starvation during their flow down the river just after hatching (Moriyama et al., 1998; Iguchi and Mizuno, 1999; Tamada, 2008, 2009). The smaller body size at maturation in lentic species (Takahashi and Okazaki, 2002) probably favors smaller eggs for increased fecundity. These factors may explain the smaller egg size in lentic species.

The third pattern of life history transformations, from fluvial (R. flumineus) to lentic changed from a small size (ancestral amphidromous species) to a small size (Rhinogobius sp. TO) through a large state (R. flumineus) in this lineage. Although the ancestral reconstruction for this lineage was not very strongly supported by the MuSSE analysis, this pattern is supported by the following considerations: (a) Rhinogobius sp. TO derived most likely from a lineage of $R$.

569 flumineus, and (b) the very restricted distribution of Rhinogobius sp. TO (around the Ise Bay area) 570 is included within the wide range of $R$. flumineus. These suggest that the former species is the one 571 that colonized from fluvial to lentic environments, such as the lake or marsh that existed around 572 the present Ise Bay area (the Paleo-Lake Tokai), as discussed above.

573 The present wetland environment in the Ise Bay area is inhabited by several highly endemic 574 species, including freshwater fishes (Pseudorasbora pugnax, Cobitis minamorii tokaiensis, as well 
as Rhinogobius sp. TO; Kawamura, 2006; Nakajima, 2012; Kawase and Hosoya, 2015), aquatic hemipteran insects Nepa hoffmanni, and plants (e.g., magnoliacean Magnolia stellata; Ueda, 2002); these suggest that such environment has been maintained for a long period. The small egg size and body size in Rhinogobius sp. TO are likely the characters representing this adaptation. The dwarf morphology of Rhinogobius sp. TO is very similar to that of other lentic species (Rhinogobius sp. BF and Rhinogobius sp. BW), and these three forms were treated as a single species until recently (Akihito et al., 2002; Suzuki and Mukai, 2010). However, the present study clarified that Rhinogobius sp. TO belongs to a different lineage from Rhinogobius sp. BF and Rhinogobius sp. BW, indicating that their lentic life history and dwarf morphology were the result of convergent evolution. The evolutionary change suggested in the freshwater $R$. flumineus and Rhinogobius sp. TO lineage emphasizes the adaptive flexibility of Rhinogobius fishes.

The reconstructed life history changes did not include the changes from freshwater (fluvial or lentic) to amphidromous types. The amphidromous life history requires adaptations to migrating behavior and salinity tolerance, which are not required for freshwater fish (McDowall, 2004). In fact, some freshwater Rhinogobius species have weakened or completely lost their salinity tolerance (Rhinogobius sp. YB and Rhinogobius sp. BB; Hirashima and Tachihara, 2000). Loss of standing genetic variation through purifying selection or bottleneck during colonization of freshwater environment may have prevented the freshwater species from re-acquiring the amphidromous life. Competition or hybridization with prior amphidromous residents may also prevent this reversal in evolution.

In summary, the considerable species diversity of Rhinogobius has been promoted and maintained by parallel life history divergence through colonization of and adaptation to various freshwater habitats, including flowing waters, marshes, and lakes. The life history divergence involving the changes in migration patterns and egg size probably functions as a direct mechanism of reproductive isolation among the divergent populations. To elucidate the whole picture of life 
600 history evolution in Rhinogobius, further phylogenetic analysis using comprehensive taxon

601 sampling from East/Southeast Asia is necessary.

602

603 Acknowledgments

604 We thank M. Hosokawa, N. Oseko, M. Aizawa, T. Abe, M. Kumazawa, Y. Miyazaki, Y. Kanzaki,

605 T. Tsunagawa, S. Nakamura, R. Tabata, H. Nakagawa, T. Mishina, T. Nakano, Y. Kano, C.-G.

606 Zhang, R. Nishiguchi, and Hakuryo Junior and Senior High School Biology Club for collecting

607 samples, A. Iwata, M. Kondo and K. Maeda for giving valuable comments and precious literature,

608 E. Kawaguchi for helping sequencing analysis, T. Fujisawa for giving helpful comments for

609 phylogenetic analysis, and the two anonymous reviewers, the handling editor and members of

610 Laboratory of Animal Ecology of Kyoto University for giving helpful comments. This study was

611 partially supported by JSPS KAKENHI (nos. 21370035, 23370041, 26291079 and 26250044) and

612 "Formation of a Strategic Base for Biodiversity and Evolutionary Research: from Genome to

613 Ecosystem” of the GCOE.

614

615

References

616

Agorreta, A., San Mauro, D., Schliewen, U., Van Tassell, J.L., Kovačić, M., Zardoya, R., Rüber, L.,2013. Molecular phylogenetics of Gobioidei and phylogenetic placemant of European gobies.

618 Mol. Phylogenet. Evol. 69, 619-633.

619 Akihito, Sakamoto, K., Ikeda, Y., Sugiyama, K., 2002. Gobioidei, in: Nakabo, T. (Ed.), Fishes of 620 Japan with pictorial keys to the species, English edition. Tokai University Press, Tokyo, pp. $621 \quad 1139-1310$.

622 Akihito, Sakamoto, K., Ikeda, Y., Aizawa, M., 2013. Gobioidei, in: Nakabo, T. (Ed.), Fishes of

623 Japan with pictorial keys to the species, Third edition. Tokai University Press, Tokyo, pp.

624 1347-1608. (In Japanese) 
625 Aonuma, Y., Iwata, A., Asahida, T., Ida, H., Kobayashi, T., 1998. Genetic variation of Rhinogobius

626 fishes (Pisces: Gobiidae) around the East China Sea with notes on its zoogeography. DNA

627 polymorphism 6, 116-122. (in Japanese)

628 Ballard, J.W.O., Whitlock, M.C., 2004. The incomplete natural history of mitochondria. Mol. Ecol.

$629 \quad 13,729-744$.

630 Bernatchez, L., Renaut, S., Whiteley, A.R., Derome, N., Jeukens, J., Landry, L., Lu, G., Nolte, 631 A.W., Østbye, K., Roger, S.M., St-Cyr, J., 2010. On the origin of species: insights from the 632 ecological genomics of lake whitefish. Phil. Trans. R. Soc. B 365, 1783-1800.

633 Betancur-R., R., Ortí, G., Stein, A.M., Marceniuk, A.P., Pyron, A., 2012. Apparent signal of 634 competition limiting diversification after ecological transitions from marine to freshwater habitats. Ecol. Lett. 15, 822-830.

636 Betancur-R., R., Broughton, R.E., Wiley, E.O., Carpenter, K., Lopez, J.A., Li, C., Holcroft, N.I., 637 Arcila, D., Sanciangco, M., Cureton, J., Zhang, F., Buser, T., Campbell, T., Rowley, T., 638 Ballesteros, J.A., Lu. G., Grande, T., Arratia, G., Ortí, G., 2013. The tree of life and a new 639 classification of bony fishes. Plos Curr. Tree of Life 2013. http://dx.doi.org/10.1371/currents.tol.53ba26640df0ccaee75bb165c8c26288 (Apr. 18).

641 Betancur-R., R., Wiley, E., Bailly, N., Miya, M., Lecointre, G., Ortí, G., 2014. Phylogenetic classification of bony fishes_version 3. http://www.deepfin.org/Classification_v3.htm

643 Betancur-R., R., Ortí, G., Pyron, R.A., 2015. Fossil-based comparative analyses reveal ancient marine ancestry erased by extinction in ray-finned fishes. Ecol. Lett. 18, 441-450.

Bossu, C.M., Near, T.J., 2009. Gene trees reveal repeated instances of mitochondrial DNA introgression in orangethroat darters (Percidae: Etheostoma). Syst. Biol. 58, 114-129. Gobiidae) from northern Vietnam. J. Nat. Hist. 39, 1407-1429.

649 Chen, I-S., Cheng, Y.H., Shao, K.T., 2008. A new species of Rhinogobius (Teleostei: Gobiidae) 
from the Julongjiang Basin in Fujian Province, China. Ichthyol. Res. 55, 335-343.

651 Chiba, S., 2002. Ecological diversity and speciation in land snails of the genus Mandaria from the $652 \quad$ Bonin Islands. Popul. Ecol. 44, 179-187.

653 Closs, G.P., Hicks, A.S., Jellyman, P.G., 2013. Life histories of closely related amphidromous and non-migratory fish species: a trade-off between egg size and fecundity. Freshw. Biol. 58, $1162-1177$.

Darriba, D., Taboada, G.L, Doallo, R., Posada, D., 2012. jModelTest 2: more models, new heuristics and parallel computing. Nature Methods 9, 772.

Drummond, A.J., Suchard, M.A., 2010. Baysian random local clocks, or one rate to rule them all. BMC Biol. 8, 114.

Drummond, A.J., Suchard, M.A., Xie, D., Rambaut, A., 2012. Bayesian phylogenetics with BEAUti and the BEAST 1.7. Mol. Biol. Evol. 29, 1969-1973.

662 FitzJohn, R.G., 2012. Diversitree: comparative phylogenetic analyses of diversification in R. 663 Methods Ecol. Evol. 3, 1084-1092.

664 Gernhard, T., 2008. The conditioned reconstructed process. J. Theor. Biol. 253, 769-778.

665 Goldberg, E.E., Igić, B., 2008. On phylogenetic tests of irreversible evolution. 62, 2727-2741.

666 Goto, A., Andoh, T., 1990. Genetic divergence between the sibling species of river-sculpin, Cottus amblystomopsis and C. nozawae, with special reference to speciation. Environ. Biol. Fish. 28, 257-266.

Harvey, P.H., Pagel, M.D., 1991. The comparative method in evolutionary biology. Oxford University Press, Oxford.

Heled, J., Drummond, A.J., 2010. Bayesian inference of species trees from multilocus data. Mol. Biol. Evol. 27, 570-580.

Hirashima, K., Tachihara, K., 2000. Embryonic development and morphological changes in lavae and juveniles of two land-locked gobies, Rhinogobius spp. (Gobiidae), on Okinawa Island. Jpn. 
J. Ichthyol. 47, 29-41. (in Japanese with English abstract)

676

677

678

679

680

681

682

683

684

685

686

687

688

689

690

691

692

693

694

695

696

697

698

Hirashima, K., Tachihara, K., 2006. Longitudinal distribution and dietary habitats of the genus Rhinogobius in the Genka River of northern Okinawa Island, Japan. Jpn. J. Ichthyol. 53, 71-76. (in Japanese with English abstract)

Iguchi, K., Mizuno, N., 1999. Early starvation limits survival in amphidromous fishes. J. Fish Biol. 54, 705-712.

Imaizumi, T., Tamura, T., 1984. Geomorphology of the Chichijima and Hahajima Islands. Bull. Ogasawara Res. 8, 3-11. (in Japanese)

Iwata, A., 2001a. Rhinogobius sp. BB, in: Kawanabe, H., Mizuno, N., Hosoya, K. (Eds.), Freshwater Fishes of Japan, 3rd ed. Yama-Kei Publishers, Tokyo, p. 599. (in Japanese)

Iwata, A., 2001b. Rhinogobius sp. YB, in: Kawanabe, H., Mizuno, N., Hosoya, K. (Eds.), Freshwater Fishes of Japan 3rd ed. Yama-Kei Publishers, Tokyo, p. 598. (in Japanese)

Kaizuka, S., 1977. Geology and geomorphology of the Bonin Island. Bull. Ogasawara Res. 1, 2934. (in Japanese)

Kano, Y., Nishida, S., Nakajima, J., 2012. Waterfalls drive parallel evolution in a freshwater goby. Ecol. Evol. 2, 1805-1817.

Katoh, M., Nishida, M., 1994. Biochemical and egg size evolution of freshwater fishes in the Rhinogobius brunneus complex (Pisces, Gobiidae) in Okinawa, Japan. Biol. J. Linnean Soc. 51, 325-335.

Kawabe, T., 1994. Biwako no Oitachi (Formation of Lake Biwa), in: Research Group for Natural History of Lake Biwa (Ed.), Biwako no Shizenshi (The Natural History of Lake Biwa). Yasaka Shobo, Tokyo, pp. 21-132. (in Japanese)

Kawamura, K., 2006. Pseudorasbora pumila subsp. sensu Nakamura 1969, in: Natural environment division, department of environment and forestry, Mie Prefecture (Ed.), Red data 
book of Mie Prefecture 2005, Animals. Mie Prefecture Environmental Conservation Agency, Tsu, p. 142. (in Japanese)

701

702

703

704

705

706

707

708

709

710

711

712

713

714

715

716

Kawase, S., Hosoya, K., 2015. Pseudorasbora pugnax, a new species of minnow from Japan, and redescription of P. pumila (Teleostei: Cyprinidae). Ichthyol. Explor. Freshw. 25, 289-298.

Keith, P., Lord, C., 2011. Tropical freshwater Gobies: Amphidromy as a life cycle, in: Patzner, R.A., Van Tassell, J.L., Kovačič, M., Kapoor, B.G. (Eds.), The biology of gobies. Science Publishers, Enfield, New Hampshire, pp. 119-128.

Kondo, M., Maeda, K., Hirashima, K., Tachihara, K., 2013. Comparative larval development of three amphidromous Rhinogobius species making reference to their habitat preferences and migration biology. Mar. Fresh. Res. 64, 249-266.

Lanfear, R., Calcott, B., Ho, S.Y.W., Guindon, S., 2012. PartitionFinder: combined selection of partitioning schemes and substitution models for phylogenetic analyses. Mol. Biol. Evol. 29, 1695-1701.

Larkin, M.A., Blackshields, G., Brown, N.P., Chenna, R., McGettigan, P.A., McWilliam, H., Valentin, F., Wallace, I.M., Wilm, A., Lopez, R., Thompson, J.D., Gibson, T.J., Higgins, D.G., 2007. Clustal W and Clustal X version 2.0. Bioinformatics 23, 2947-2948.

Lee, C.E., Bell, M.A., 1999. Causes and consequences of recent freshwater invasions by saltwater animals. Trends Ecol. Evol. 14, 284-288.

Li, C., Ortí, G., Zhang, G., Lu, G., 2007. A practical approach to phylogenomics: the phylogeny of ray-finned fish (Actinopterygii) as a case study. BMC Evol. Biol. 7, 44.

Losos, J.B., 2009. Lizards in an Evolutionary Tree: ecology and adaptive radiation of anoles. University of California Press, Berkeley and Los Angeles, California.Maddison, D.R., Maddison, W.P., 2000. MacClade 4: Analysis of phylogeny and character evolution. Version 4.0. Sinauer, Associates, Sunderland, Massachusetts. 
723 Maddison, D.R., Maddison, W.P., 2000. MacClade 4: Analysis of phylogeny and character

724 evolution. Version 4.0. Sinauer, Associates, Sunderland, Massachusetts.

725 Maddison, W.P., 1997. Gene trees in species trees. Syst. Biol. 46, 523-536.

726 Maddison, W.P., 2006. Confounding asymmetries in evolutionary diversification and character 727 change. Evolution 60, 1743-1746.

728 Maddison, W.P., Midford, P.E., Otto, S., 2007. Estimating a binary character's effect on speciation 729 and extinction. Syst. Biol. 56, 701-710.

730 Makinouchi, T., 2001. Stratigraphy of the Tokai group and evolutional process of the Lake Tokai 731 sediment basin. Sci. Rep. Toyohashi Mus. Nat. Hist. 11, 33-39. (In Japanese with English 732 abstract)

733 Masuda, Y., Ozawa, T., Enami, S., 1989. Genetic differentiation among eight color types of the freshwater goby, Rhinogobius brunneus, from western Japan. Jpn. J. Ichthyol. 36, 30-41.

McDowall, R.M., 2001. Diadromy, diversity and divergence: implications for speciation processes

\section{7} in fishes. Fish Fish. 2, 278-285.

738

McDowall, R.M., 2004. Ancestry and amphidromy in island freshwater fish fauna. Fish Fish. 5, 75-85.

McDowall, R.M., 2007. On amphidromy, a distinct form of diadromy in aquatic organisms. Fish

\section{1} Fish. 8, 1-13.

McKinnon, J.S., Mori, S., Blackman, B.K., David, L., Kingsley, D.M., Jamleson, L., Chou, J.,

743 Meyers, P.A., Takemura, K., Horie, S., 1993. Reinterpretation of late Quaternary sediment chronology of Lake Biwa, Japan, from correlation with marine glacial-interglacial cycles. Quat. Res. 39, 154-162. 
746 Mizuno, N., 1960. Study on a freshwater goby, Rhinogobius similis Gill, with a proposition in the

747 relationships between land locking and speciation of some freshwater gobies in Japan. Mem.

$748 \quad$ Coll. Sci. Univ. Kyoto B, 27, 97-115.

749 Mizuno, N., 1982. Study on the fish, “Yoshinobori” Rhinogobius similis Gill—V 4 kei no

750 chiritekibunpu to sougosayou (Geographic distribution and interaction between 4 types).

751 Tansuigyo 8, 27-38. (in Japanese)

752 Mizuno, N., 1987. Yoshinobori rui (Genus Rhinogobius), in: Mizuno, N., Goto, A. (Eds.), Nihon no tansuigyo - sono bunpu, heni, syubunka wo megutte (Freshwater fish in Japan-distribution,

Mizuno, N., 2001. Rhinogobius, in: Kawanabe, H., Mizuno, N., Hosoya, K., (Eds.), Freshwater Fishes of Japan 3rd ed. Yama-Kei Publishers, Tokyo, p. 584. (in Japanese)

Moriyama, A., Yanagisawa, Y., Mizuno, N., Omori, K., 1998. Starvation of drifting goby larvae due to retention of free embryos in upstream reaches. Environ. Biol. Fish. 52, 321-329.

Mukai, T., 2010. Hikakukeitouchirigaku kara mita Ryukyurettou no tansuigyorui sou no seiritsu (Formation of freshwater fish fauna in the Ryukyu Archipelago-a comparative phylogenetic Japanese)

Mukai, T., Nakamura, S., Suzuki, T., Nishida, M., 2005. Mitochondrial DNA divergence in yoshinobori gobies (Rhinogobius species complex) between the Bonin Islands and the JapanRyukyu Archipelago. Ichthyol. Res. 52, 410-413. yoshinobori gobies (Rhinogobius kurodai and related species) in the irrigation ponds in southern Suzuka, Mie Prefecture, Japan, and their phylogenetic analysis. Bull. Biogeogr. Soc. 
Jpn. 67, 15-24. (In Japanese with English abstract)

771 Mukai, T., Takahashi, H., 2010. Shukankouzatsu wo tomonau keitouchiri-Shu no jittai to bunpuiki keisei (Phylogeography with interspecific hybridization-entity of species and formation of distribution), in: Watanabe, K., Takahashi, H. (Eds.), Tansuigyorui chiri no shizenshi (Natural history of freshwater fish geography). Hokkaido University Press, Sapporo, pp. 137-152. (in Japanese)

Nakajima, J., 2012. Taxonomic study of the Cobitis striata complex (Cypriniformes, Cobitidae) in Japan. Zootaxa 3586, 103-130.

Near, T.J., Bossu, C.M., Bradburd, G.S., Carlson, R.L., Harrington, R.C., Hollingsworth JR., P.R., Keck, B.P., Etnier, D.A., 2011. Phylogeny and temporal diversification of Darters (Percidae: Etheostomatinae). Syst. Biol. 60, 565-595.

Nishida, M., 1985. Substantial genetic differentiation in Ayu, Plecoglossus altivelis, of the Japan and Ryukyu Islands. Bull. Jpn. Soc. Sci. Fish. 51, 1269-1274.

Nishida, M., 1986. Geographic variation in the molecular, morphological and reproductive character of the ayu Plecoglossus altivelis (Plecoglossidae) in the Japan-Ryukyu Archipelago. Jpn. J. Ichthyol. 33, 232-248.

Nishida, M., 1994. Yoshinobori rui ni okeru seikatsushi heni to syubunka (Life history variation and speciation in the genus Rhinogobius), in: Goto, A., Tsukamoto, K., Maekawa, K. (Eds.), Kawa to umi wo kaiyu suru tansuigyo-seikatushi to shinka (Freshwater fish migrating between river and the ocean-life history and evolution). Tokai University Press, Tokyo, pp. 154-169. (in Japanese)

Nishida, M., 2001. Evolutionary process toward large egg: Rhinogobius, in: Goto, A., Iguchi, K. (Eds.), Evolutionary biology of egg size in aquatic animals. Kaiyusha, Tokyo, pp. 149-170. (in Japanese)

Nishijima, S., 1968. Two forms of the gobioid fish Rhinogobius brunneus from Okinawa-Jima, 
Ryukyu Islands. Zool. Mag. 77, 397-398. (in Japanese)

796

Nosil, P., 2012. Ecological speciation. Oxford University Press, Oxford.

Oijen, M.J.P., Suzuki, T., Chen, I.S., 2011. On the earliest published species of Rhinogobius. with a redescription of Gobius brunneus Temminck and Schlegel, 1845. J. Natn. Taiwan Mus. 64, $1-17$.

Oshiro, N., Nishijima, S., 1978. An observation on the juveniles of "Yoshinobori" (Gobiidae) in the sea-waters. Biol. Mag. Okinawa 16, 17-22. (in Japanese.)

Osozawa, S., Shinjo, R., Armid, A., Watanabe, Y., Horiguchi, T., Wakabayashi, J., 2012.

Palaeogeographic reconstruction of the 1.55 Ma synchronous isolation of the Ryukyu Islands, Japan, and Taiwan and inflow of the Kurishio warm current. Int. Geol. Rev. 54, 1369-1388.

Ota, H., 1998. Geographic patterns of endemism and speciation in amphibians and reptiles of the Ryukyu Archipelago, Japan, with special reference to their Paleogeographical implications. Res. Poplu. Ecol. 40, 189-204.

Paradis, E., Claude, J., Strimmer, K., 2004. APE: analysis of phylogenetics and evolution in R language. Bioinformatics 20, 289-290.

Pyron, R.A., Burbrink, F.T., 2014. Early origin of viviparity and multiple reversions to oviparity in squamate reptiles. Ecol. Lett. 17, 13-21.

R Development Core Team, 2014. R: A language and environment for statistical computing. R Foundation for Statistical Computing, Vienna, Austria. http://www.R-project.org

Rambaut, A., 2009. Fig Tree v1.3.1 < http://tree.bio.ed.ac.uk/software/figtree/>

Rambaut, A., Suchard, M.A., Xie, D., Drummond, A.J., 2013. Tracer v1.5.0 http://beast.bio.ed.ac.uk/Tracer

Ronquist, F., Huelsenbeck, J.P., 2003. MrBayes 3: Bayesian phylogenetic inference under mixed models. Bioinformatics 19, 1572-1574. 
819 Rozen, S., Skaletsky, H.J., 2000. Primer3 on the WWW for general users and for 15 biologist 820 programmers, in: Krawetz, S., Misener, S., (Eds.), Bioinformatics Methods and Protocols: 821 Methods in Molecular Biology. Humana Press, Totowa, NJ, pp. 365-386.

822 Rüber, L., Agorreta, A., 2011. Molecular systematics of gobioid fishes, in: Patzner, R.A., Van 823 Tassell, J.L., Kovačič, M., Kapoor, B.G. (Eds.), The biology of gobies. Science Publishers, 824 Enfield, New Hampshire, pp. 23-50.

825 Sakai, H., Ikoma, K., Frolov, S.J., Yamazaki, Y., Takahashi, H., Ida, H., 2000. Morphological 826 features of a Russian freshwater goby, Rhinogobius lindbergi (Pisces: Gobiidae), and its genetic relationships to Japanese species. Biogeography 2, 51-61.

828 Schluter, D., 2000. The ecology of adaptive radiation. Oxford University Press, Oxford.

829 Schluter, D., 2009. Evidence for ecological speciation and its alternative. Science 323, 737-741.

830 Seehausen, O., 2004. Hybridization and adaptive radiation. Trends Ecol. Evol. 19, 198-207.

831 Seehausen, O., 2006. African cichlid fish: a model system in adaptive radiation research. Proc. R. $832 \quad$ Soc. B 273, 1987-1998.

833 Seehausen, O., van Alphen, J.J.M., Witte, F., 1997. Cichlid fish diversity threatened by 834 eutrophication that curbs sexual selection. Science 277, 1808-1811.

835 Shimodaira, H., 2002. An approximately unbiased test of phylogenetic tree selection. Syst. Biol. 51, 492-508.

Shimodaira, H., Hasegawa, H., 2001. CONSEL: for assessing the confidence of phylogenetic tree selection. Bioinformatics 17, 1246-1247.

839 Stamatakis, A., 2006. RAxML-VI-HPC: Maximum likelihood based phylogenetic analysis with 840 thousands of taxa and mixed models. Bioinformatics 22, 2688-2690.

841 Suzuki, T., 1992. Ogasawara shotou chichi jima de erareta yoshinobori no 1 shu-Ogasawara 842 yoshinobori (shinshou)-(yohou) (One of the Yoshinobori species found in Chichijima in Bonin 
843 Island-Ogasawara yoshinobori (new name)-(advance report). Hyogo Freshw. Biol. 42, 5-12.

$844 \quad$ (in Japanese)

845 Suzuki, T., Sakamoto, K., 2005. Record of a gobiid fish, Rhinogobius sp. TO (Perciformes,

846 Gobiidae) from the Noubi and Okazaki plains, Japan. Bull. Biogeogr. Soc. Jpn. 60, 13-20. (in

$847 \quad$ Japanese with English abstract)

848 Suzuki, T., Shibukawa, K., Yano, K., Senou, H., 2004. A photographic guide to the gobioid fishes 849 in Japan. Heibonsha, Tokyo. (in Japanese)

850 Suzuki, T., Chen, I-S., 2011. Redescription of three species of genus Rhinogobius (Perciformes,

851 Gobiidae) described by Dr. Shigeho Tanaka. Bull. Osaka Mus. Nat. Hist. 65, 9-24. (in

$852 \quad$ Japanese with English abstract)

853 Suzuki, T., Chen, I-S., Senou, H., 2011. A new species of Rhinogobius Gill, 1859 (Teleostei:

854 Gobiidae) from the Bonin Islands, Japan. J. Mar. Sci. Tech. 19, 693-701.

855 Suzuki, T., Mukai, T., 2010. Two lentic freshwater gobies, Rhinogobius sp. BF and Rhinogobius sp.

856 TO: their morphological characteristics, distribution and present status. Jpn. J. Ichthyol. 57, 857 176-179. (In Japanese with English abstract)

858 Tabata, R., Watanabe, K., 2013. Hidden mitochondrial DNA divergence in the Lake Biwa endemic 859 goby Gymnogobius isaza: implications for its evolutionary history. Environ. Biol. Fish. 96, $860 \quad 701-712$.

861 Takahashi, S., Okazaki, T., 2002. A new lentic form of the “yoshinobori” species complex, 862 Rhinogobius spp. from Lake Biwa, Japan, compared with lake-river migrating Rhinogobius sp. 863 OR. Ichthyol. Res. 49, 333-339.

864 Tamada, K. 2000. Distribution of the spawning of four amphidromous gobies (Rhinogobius spp.) 865 in the Aizu River, Wakayama Prefecture, Japan. Jpn. J. Ichthyol. 47, 55-59. (In Japanese with $866 \quad$ English abstract) 
867 Tamada, K., 2001. Clutch size and egg size in three species of Rhinogobius complex dwelling in a 868 single stream. Jpn. J. Ichthyol. 48, 49-52. (in Japanese with English abstract)

869 Tamada, K., 2008. Variation in male mating success in the paternal nest brooder, Rhinogobius goby, along a river course. Ecol. Res. 23, 91-97.

871 Tamada, K., 2009. Variation in clutch and egg sizes in the amphidromous goby Rhinogobius sp. CB along a river course and within a spawning season. Ichthyol. Res. 56, 69-75.

Tamura, K., Peterson, D., Peterson, N., Stecher, G., Nei, M., Kumar, S., 2011. MEGA5: Molecular Evolutionary Genetics Analysis using maximum likelihood, evolutionary distance, and maximum parsimony methods. Mol. Biol. Evol. 28, 2731-2739.

Toews, D.P., Brelsford, A., 2012. The biogeography of mitochondrial and nuclear discordance in animals. Mol. Ecol. 21, 3907-3930.

Tsujimoto, H., 2008. Nishinihon ni seisoku suru shisuiiki wo konomu 3 shu no yoshinobori nit suite-shoukai to kansatsu- (3 Rhinogobius species distributed in lentic area in Western Japan) Botejyako 13, 7-15. (in Japanese)

Tsunagawa, T., Suzuki, T., Arai, T., 2010a. Migratory history of Rhinogobius sp. OR morphotype “Shimahire” as revealed by otolith Sr:Ca ratios. Ichthyol. Res. 57, 10-15

Tsunagawa, T., Suzuki, T., Arai, T., 2010b. Otolith Sr:Ca ratios of freshwater goby Rhinogobius sp. TO indicating absence of sea migrating traits. Ichthyol. Res. 57, 319-322. Land Spring-fed Mires), in: Hiroki, S. (Ed.), Satoyama no seitaigaku-sononaritachi to hozen no arikata (Ecology of satoyama-formation and conservation) The University of Nagoya Press,

889 Vega, G.C., Wiens, J.J., 2012. Why are there so few fish in the sea? Proc. R. Soc. B 279, 2323890 2329. 
891 Waters, J.M., Rowe, D.L., Burridge, C.P., Wallis, G.P., 2010. Gene trees versus species trees: 892 Reassessing life-history evolution in a freshwater fish radiation. Syst. Biol. 59, 504-517.

893 Winker, K., 2000. Migration and speciation. Nature 404, 36.

894 Yamada, T., Sugiyama, T., Tamaki, N., Kawakita, A., Kato M., 2009. Adaptive radiation of gobies 895 in the interstitial habitats of gravel beaches accompanied by body elongation and excessive 896 vertebral segmentation. BMC Evol. Biol. 9, 145.

897 Yokoyama, T., 1984. Stratigraphy of the Quaternary system around Lake Biwa and geohistory of 898 the ancient Lake Biwa, in: Horie S (Ed.), Lake Biwa, Monographiae Biologicae, 54., Dr W 899 Junk Publishers, Dordrecht, Boston, Lancaster. 43-128.

900 Yokoyama, T., Nakagawa, Y., 1991. Setonaikai no utsurikawari (Transition of the Seto Inland Sea), 901 Sanwashobou, Hyogo, Japan. (in Japanese)

902 Yoder, J.B., Clancey, E., Des Roches, S., Eastman, J.B., Gentry, L., Godsoe, W., Hagey, T.J., 903 Jochimsen, D., Oswald, B.P., Robertson, J., Sarver, B.A.J., Schenk, J.J., Spear, S.F., Harmon, 904 L.J., 2010. Ecological opportunity and the origin of adaptive radiations. J. Evol. Biol. 23, $905 \quad$ 1581-1596.

906 Yoshida, F., 1990. Stratigraphy of the Tokai Group and paleogeography of the Tokai sedimentary 907 basin in the Tokai region, central Japan. Bull. Geol. Surv. Jpn. 41, 303-340. (In Japanese with $908 \quad$ English abstract)

909 Yule, G.U., 1925. A mathematical theory of evolution: based on the conclusions of Dr. J.C. Willis. $910 \quad$ Phil. Trans. R. Soc. B 213, 21-87. 
911 Figure legends

$912 \quad$ Fig. 1.

913 A map of the collection sites. The location codes correspond to those in Table 1.

914

$915 \quad$ Fig. 2.

916 The Bayesian tree of the selected Rhinogobius species with estimated divergence time based on

917 partial mtDNA sequence data (2781 bp) inferred with BEAST. Support values are indicated

918 beside the branches (RAxML BP/ MrBayes PPM/ BEAST PPB). Only support values $>70 \%$ in

919 ML, and >0.9 in PPM and PPB are indicated. Some support values for intraspecific relationships

920 are not shown. Each bar plot indicates 95\% HPD height of the node. CA2 indicates the position of

921 calibration point 2 (formation of the Tokara Gap).

922

923 Fig. 3.

924 The maximum likelihood tree of the selected Rhinogobius species inferred from concatenated

925 sequences of six nuclear genes (myh6, RYR3, Ptr, RAG2, sreb2, and EGR3; 4755bp). Maximum

926 likelihood bootstrap values ( $>70 \%)$ and Bayesian posterior probability $(>0.9)$ are indicated

927 (BP/BPP). Some support values for intraspecific relationships are not shown.

928

$929 \quad$ Fig. 4.

930 (a) The Bayesian phylogenetic tree of the selected Rhinogobius species with ancestral state

931 reconstruction and divergence time inferred from concatenated sequences of six nuclear genes.

932 Each bar plot indicates a height of 95\% HPD of the corresponding node. Calibration points were

933 indicated as CA1 (formation of the Bonin Islands) and CA2 (formation of the Tokara Gap). Pie

934 graphs of each node indicate the proportional likelihood of the states at the node inferred by the

935 MuSSE model. Statistical support values ( $>0.9$ ) are indicated next to the major nodes. The 
936 proportional likelihood of the nodes indicated by an asterisk is inconsistent when another sample

937 of Rhinogobius sp. BF was used. (b)-(e) Phylogenetic relationships among selected species with 938 their present distribution patterns. See the Discussion section for details.

939 
Fig. 2
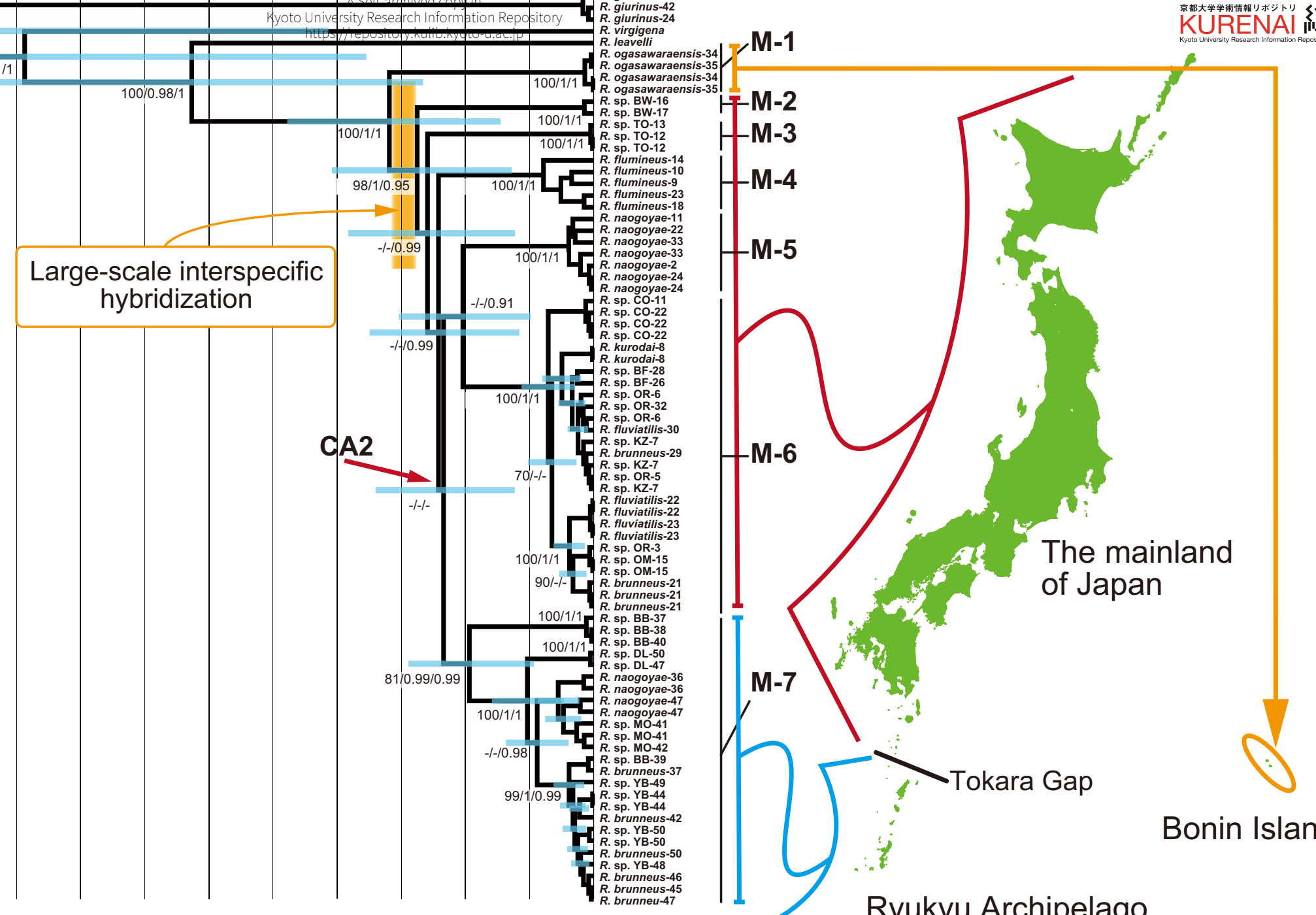

Bonin Islands 


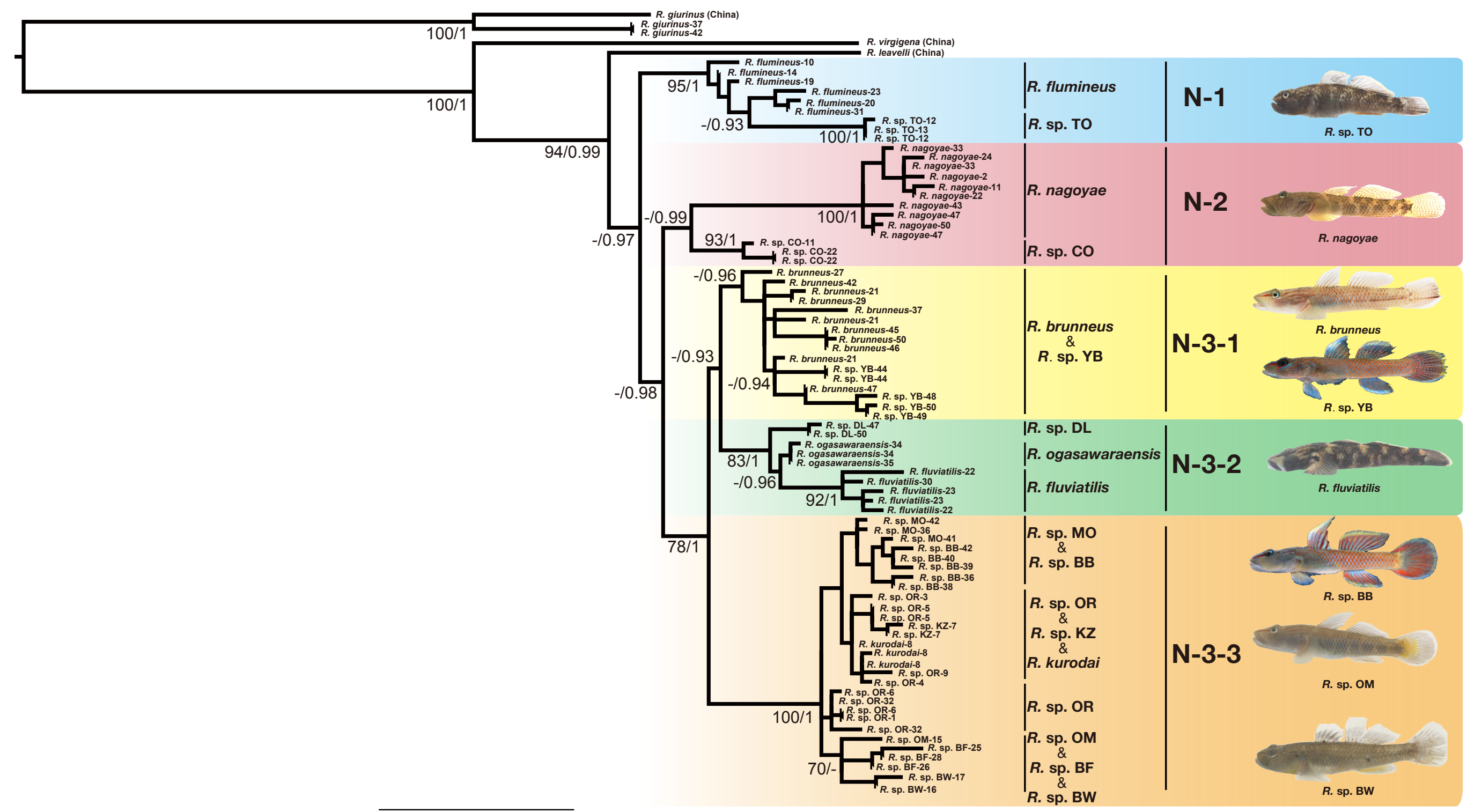

Fig. 3 
Table 1

List of samples used in this study. Locality numbers correspond to those in Fig. 1. Asterisks indicate specimens used in the MuSSE analysis (see Fig. 4a).

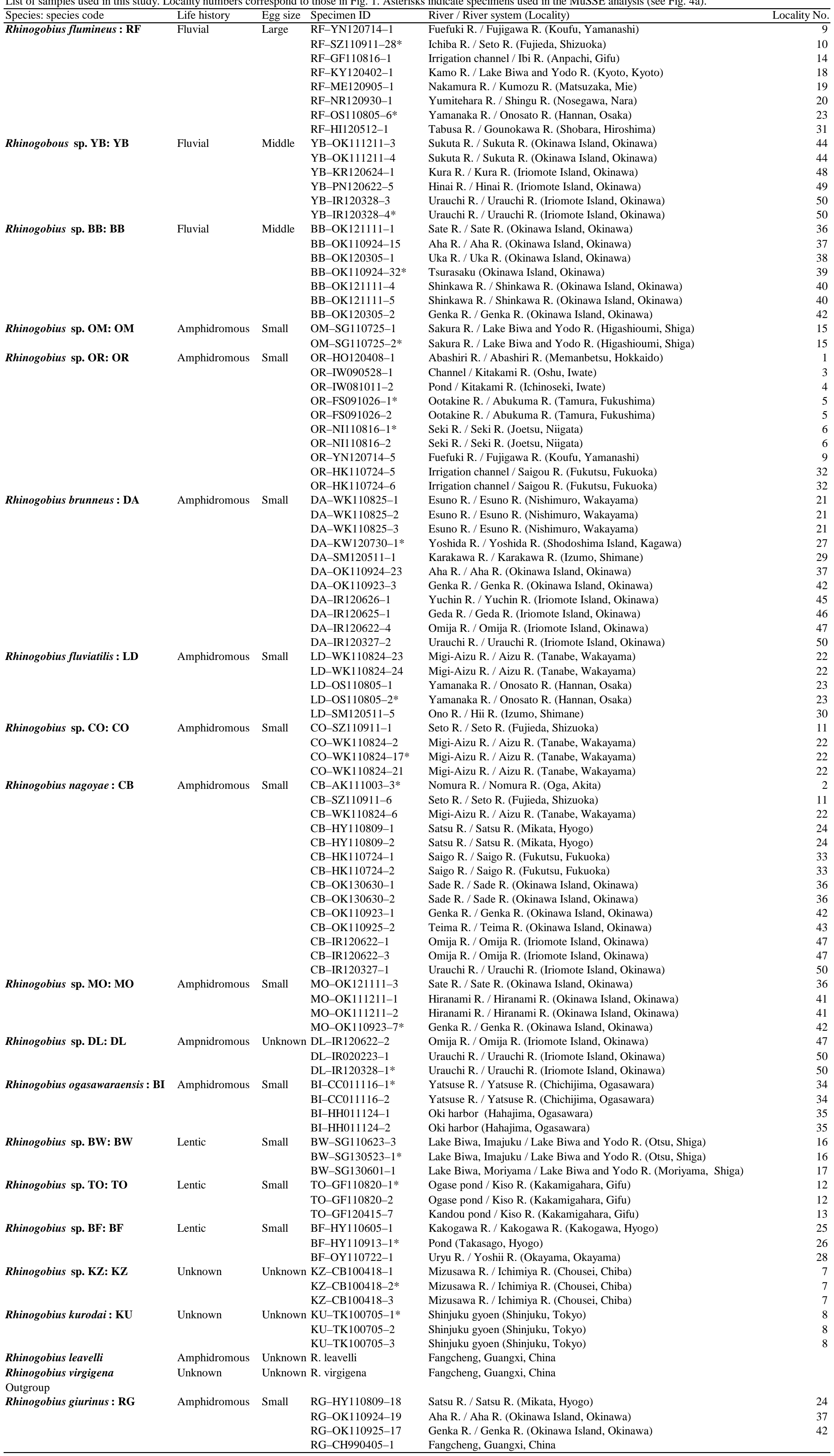


Table 2.

Estimated divergence time of major clades of Rhinogobius gobies.

\begin{tabular}{lcc}
\hline mtDNA & tMRCA(Mya, hight mean) & 95\% HPD (Mya) \\
CA2 (M-5+M-6 vs. M-7) & 1.17 & $0.62-1.70$ \\
M-5+M-6 & 1.02 & $0.49-1.52$ \\
M-7 & 0.97 & $0.47-1.44$ \\
All Japanese species & 1.59 & $0.73-2.39$ \\
nuclear DNA & & \\
CA1 (R. fluviatilis + R. ogasawaraensis) & 1.55 & $1.05-2.00$ \\
CA2 (R. nagoyae in mainland + Ryukyu) & 1.14 & $0.68-1.69$ \\
N-3-2 & 1.78 & $1.03-2.53$ \\
N-3-3 & 1.65 & $0.81-2.53$ \\
$R$ flumineus + R. sp. TO & 1.43 & $0.49-2.44$ \\
$R$. sp. OR + R. sp. KZ + R. kurodai vs. $R$. sp. MO + & 1.20 & $0.59-1.89$ \\
$R$. sp. BW + R. sp. BF + R. sp. OM & 1.10 & $0.49-1.77$ \\
$R$. sp. BW + part of $R$. sp. BF & 0.90 & $0.35-1.51$ \\
All Japanese species & 4.48 & $2.38-6.66$ \\
\hline
\end{tabular}




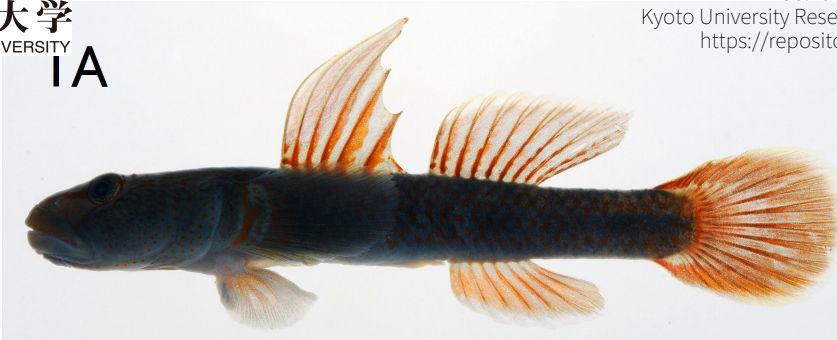

$1 \mathrm{~B}^{- \text {uacip }}$
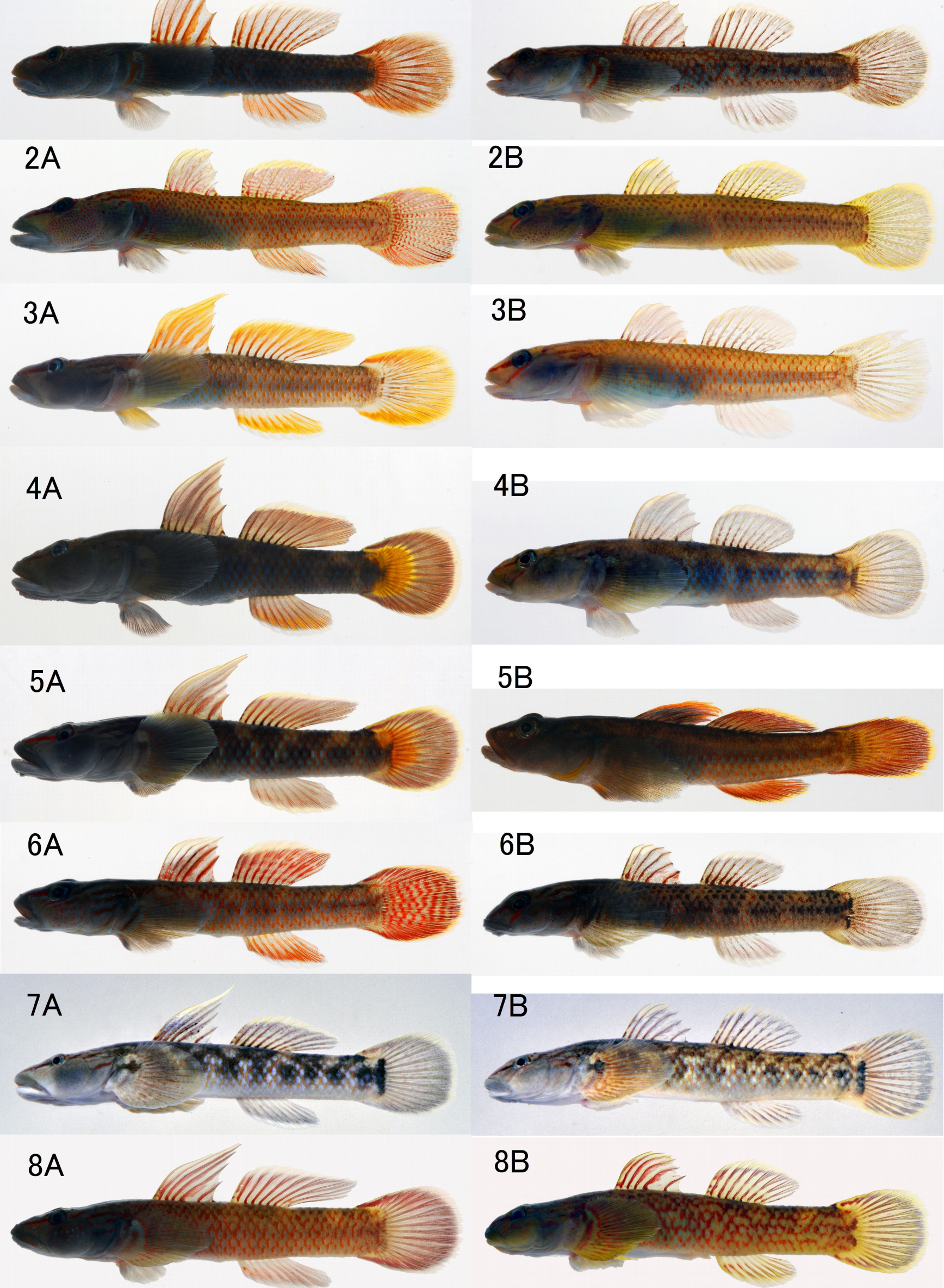

Fig. S1 Photographs of all Rhinogobius species distributed in Japan.

1: Rhinogobius flumineus (Mizuno, 1960), Nagaragawa River, Gifu Pref. A: OMNH-P 40703, male, B: OMNH-P 40704, female.

2: Rhinogobous sp. YB, Hinaigawai River, Iriomote Island, the Ryukyu Islands. A: OMNH-P 40256, male, B: OMNH-P 40255, female.

3: Rhinogobius sp. BB, Ooigawa River, Okinawa Island, the Ryukyu Islands. A: OMNH-P 40303, male, B: OMNH-P 40302, female.

4: Rhinogobius sp. OM. A: OMNH-P 40605, male, Yasugawa River, Shiga Pref., B: OMNH-P 40609, female, Ukawa-river, Shiga Pref.

5: Rhinogobius sp. OR. A: OMNH-P 40721, male, Maruyamagawa River, coast of Japan Sea of Hyogo Pref.,

B: OMNH-P 34814, male, pond, Ichinoseki, Iwate Pref.

6: Rhinogobius brunneus (Temminck and Schlegel,1845), Aikawagawa River, Nagasaki Pref. A: OMNH-P 35063, male,

B: OMNH-P 35064, female.

7: Rhinogobius fluviatilis Tanaka, 1925, Tairagawa River, Kagoshima Pref. A: OMNH-P 18393, male, B: OMNH-P 18392, female.

8: Rhinogobius sp. CO, Inouzawagawa River, Shizuoka Pref. A: OMNH-P 40616, male, B: OMNH-P 40618, female. 

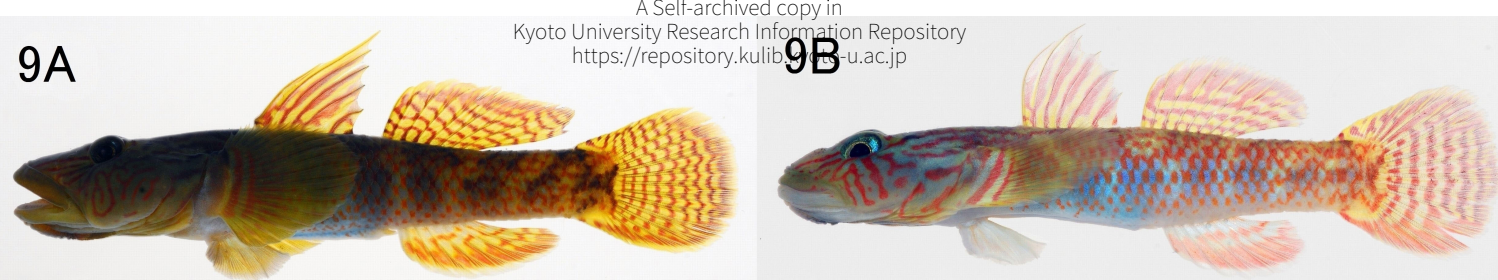

$10 \mathrm{~A}$

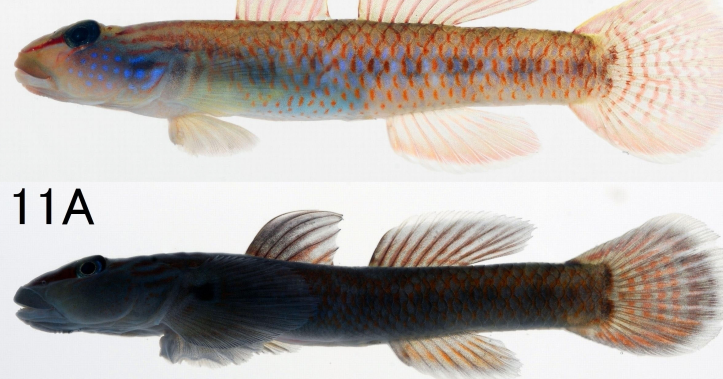

$12 \mathrm{~A}$

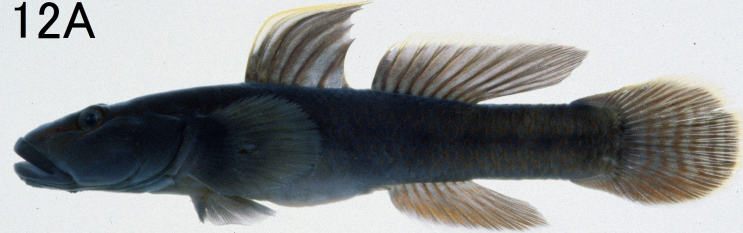

13A

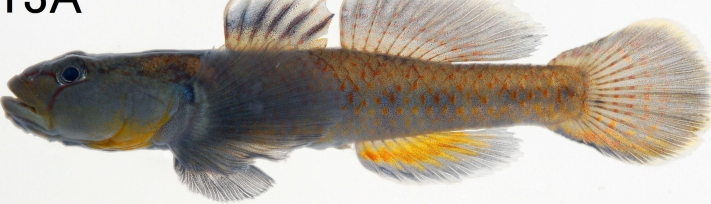

$14 \mathrm{~A}$

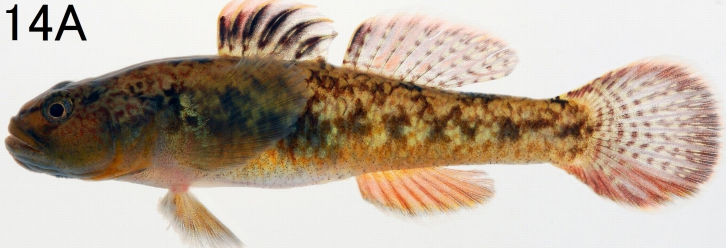

$15 A$

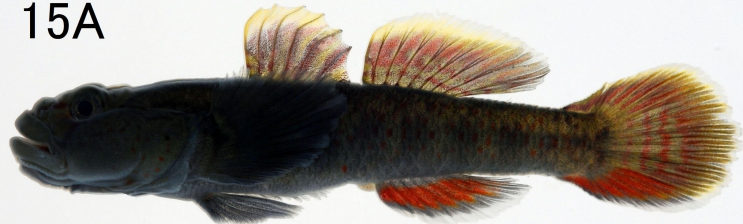

$16 \mathrm{~A}$

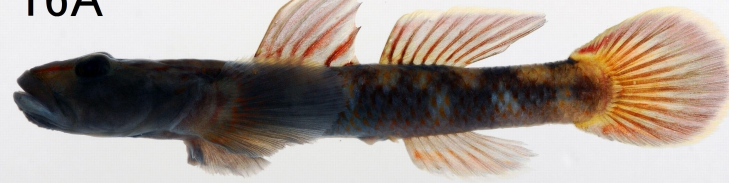

17A

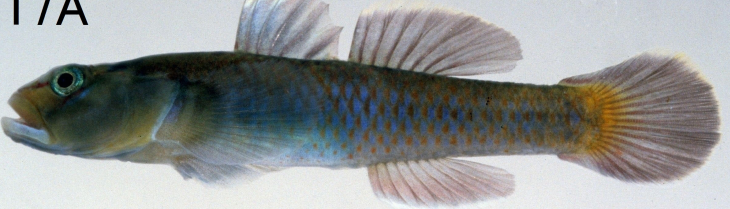

10B

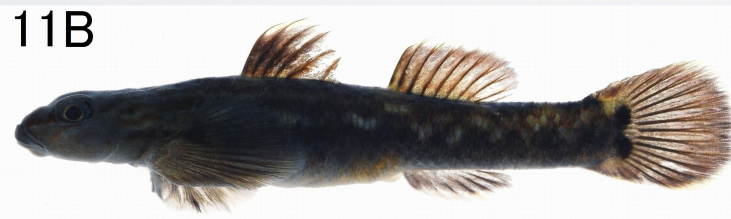

$12 B$

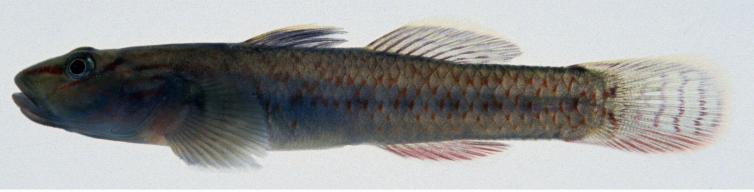

13B

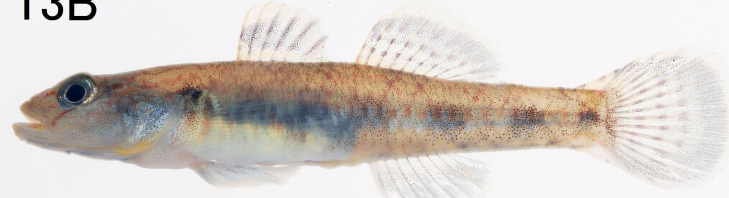

14B

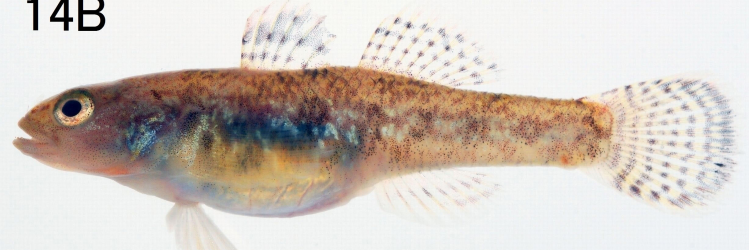

15B

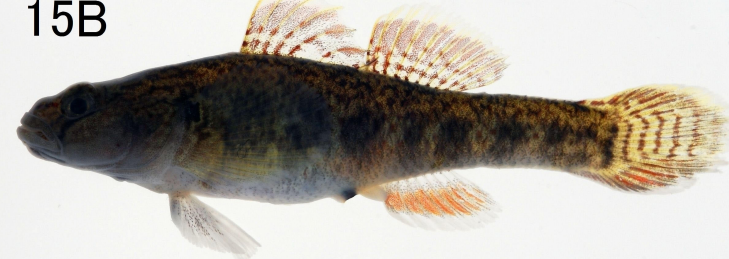

16B

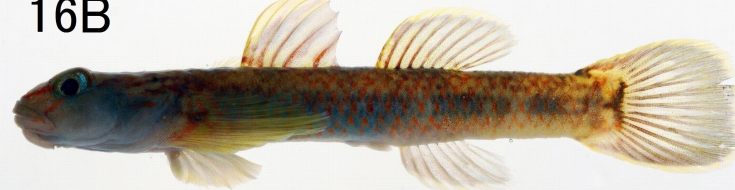

17B

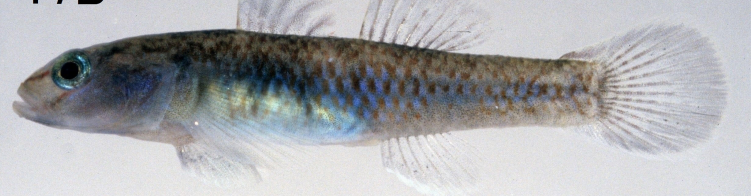

Fig. S1 Continued.

9: Rhinogobius nagoyae Jordan and Seale, 1906. A: OMNH-P 37667, male, Maruyamagawa River,

coast of Japan Sea of Hyogo Pref., B: OMNH-P 38182, male, Teimagawa River, Okinawa Island, the Ryukyu Islands.

10: Rhinogobius sp. MO, Sate River, Okinawa Island, the Ryukyu Islands. A: OMNH-P 40281, male,

B: OMNH-P 40282, female.

11: Rhinogobius sp. DL, Urauchi River, Iriomote Island, the Ryukyu Islands. A: OMNH-P 40035, male, B: OMNH-P 40036, female.

12: Rhinogobius ogasawaraensis Suzuki, Chen and Senou, 2011, Chichi Island, Ogasawara Is.

A: OMNH-P 8262, male, Yatsusegawa River, B: OMNH-P 8257, female, Oomura.

13: Rhinogobius sp. BW, Ukawa, Lake Biwa, Shiga Pref. A: OMNH-P 23928, male, B: OMNH-P 23929, female.

14: Rhinogobius sp. TO, Kanaregawa River, Aichi Pref. A: OMNH-P 40705, male, B: OMNH-P 40708, female.

15: Rhinogobius sp. BF, Maruyamagawa River, coast of Japan Sea of Hyogo Pref. A: OMNH-P 37710, male, B: OMNH-P 37711, female.

16: Rhinogobius sp. KZ, Isumigawa River, Chiba Pref. A: OMNHP 40656, male, B: OMNHP 40663, female.

17: Rhinogobius kurodai (Tanaka. 1908), Moat, Chiyouda, Tokyo. A: OMNH-P 21132, male, B: OMNH-P 21136, female. 
(a) myh6

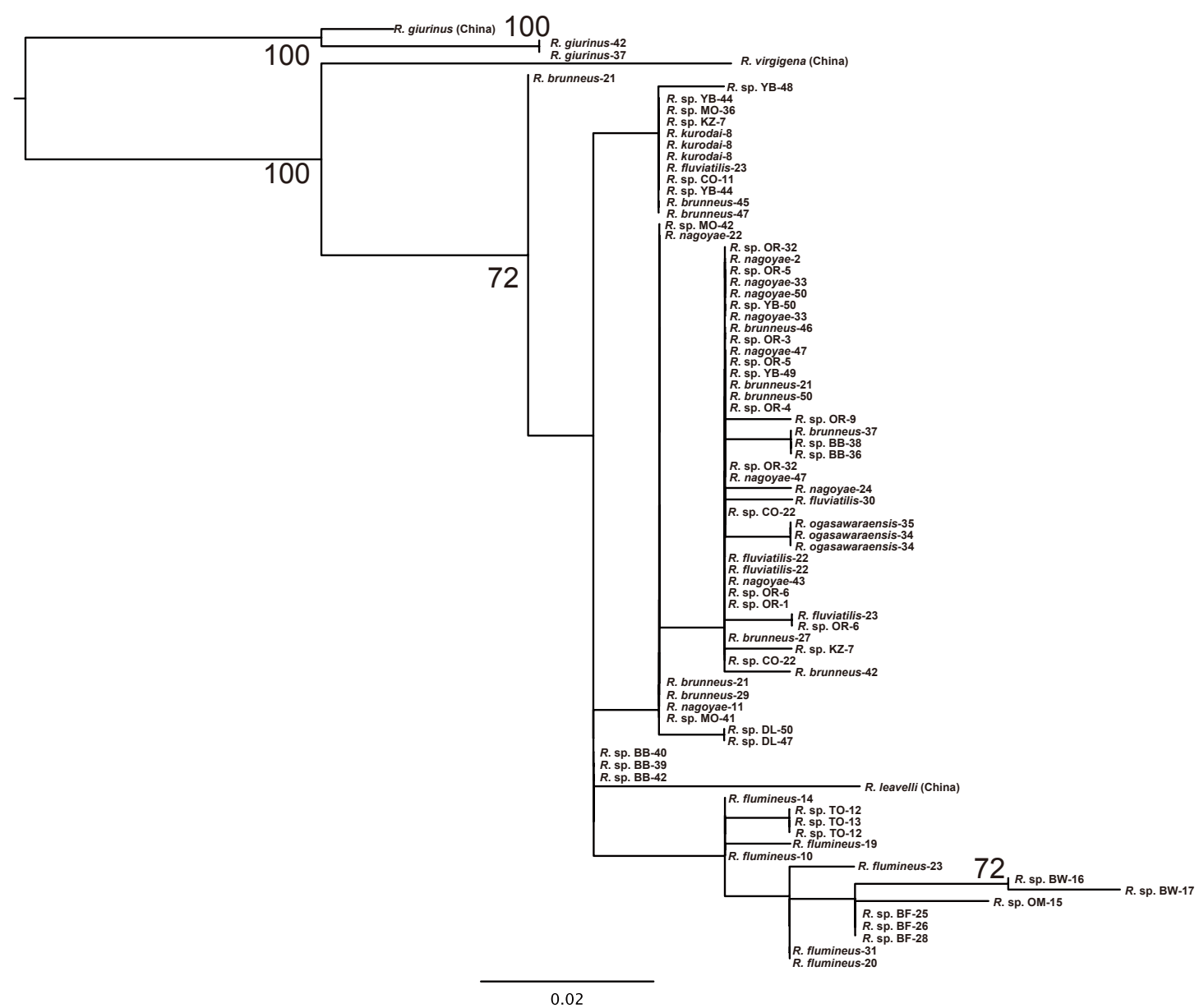

(b) RYR3

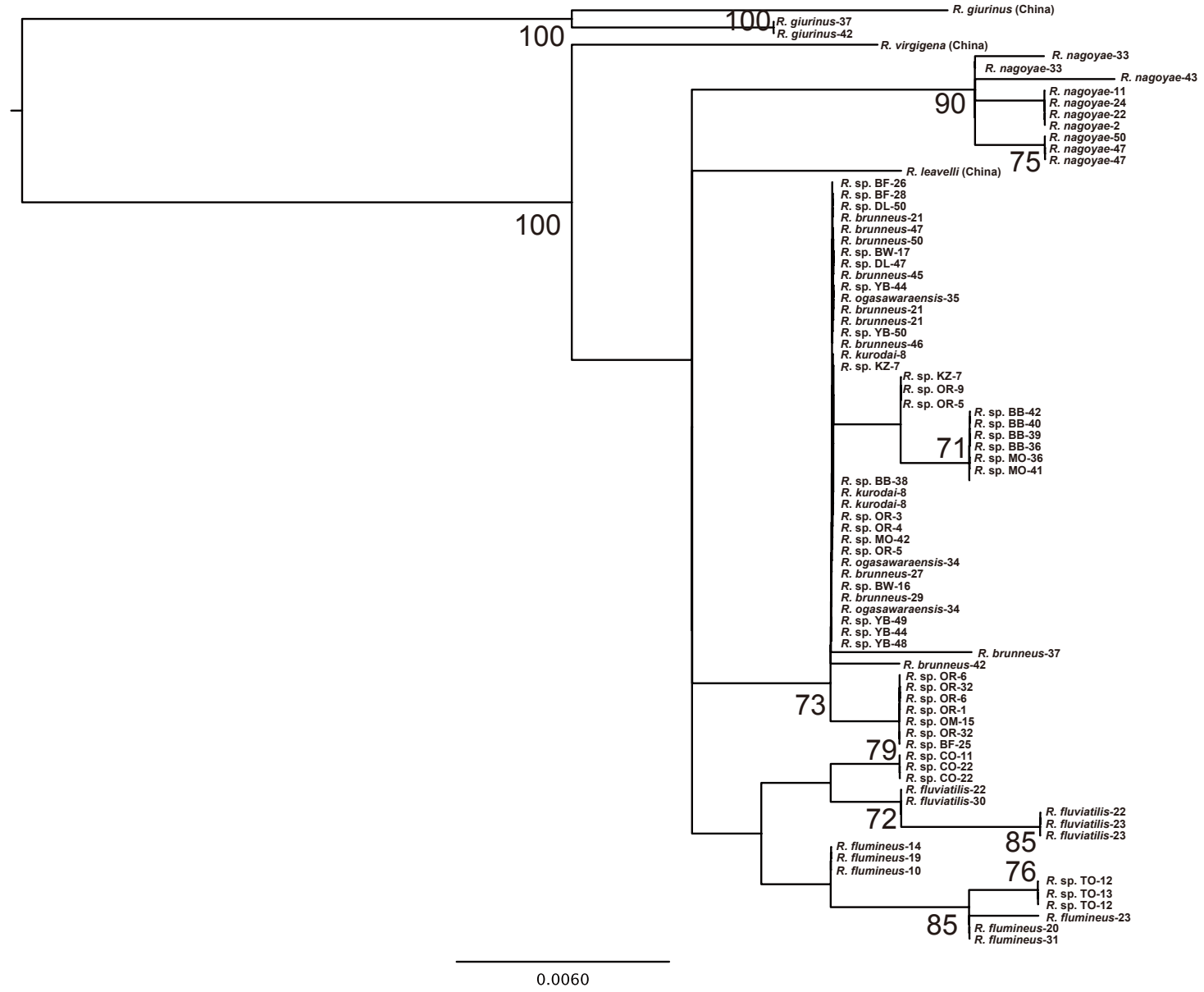

Fig. S2 Maximum likelifood trees of the selected Rhinogobius species based on respective nuclear gene sequences. Bootstrap values of $>70 \%$ are indicated. 
(c) Ptr

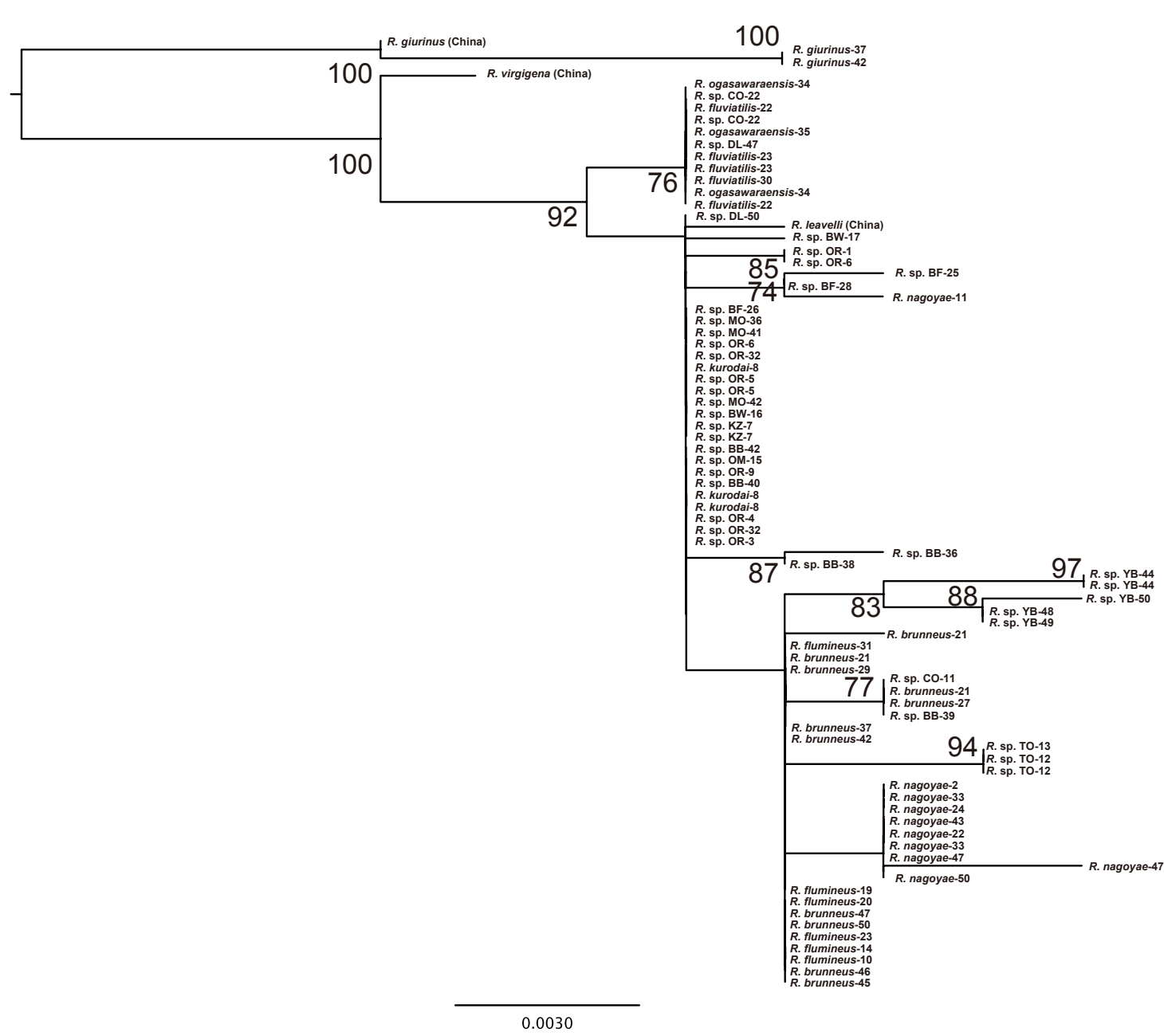

(d) RAG2

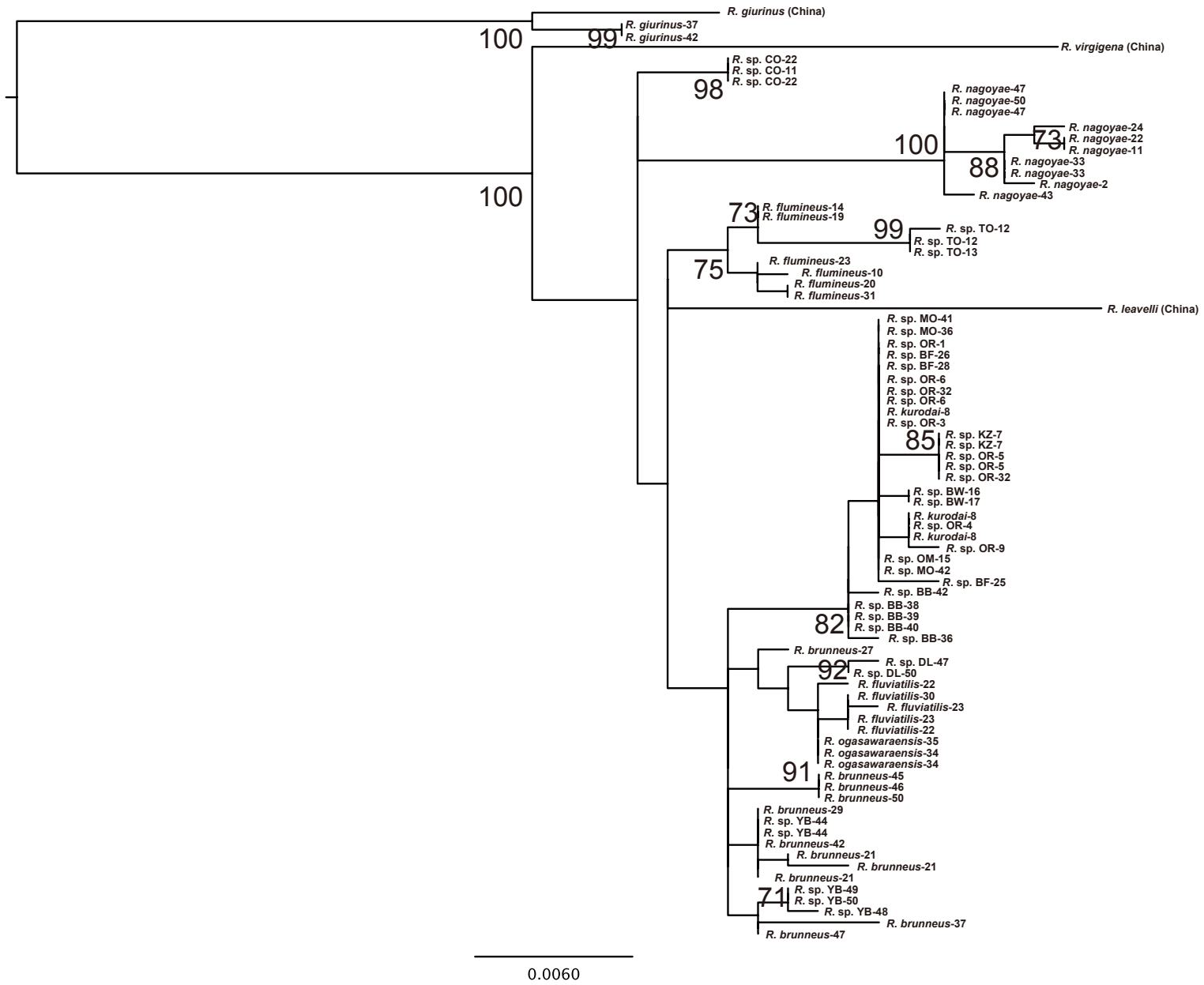

Fig. S2 Continued. 
(e) sreb2

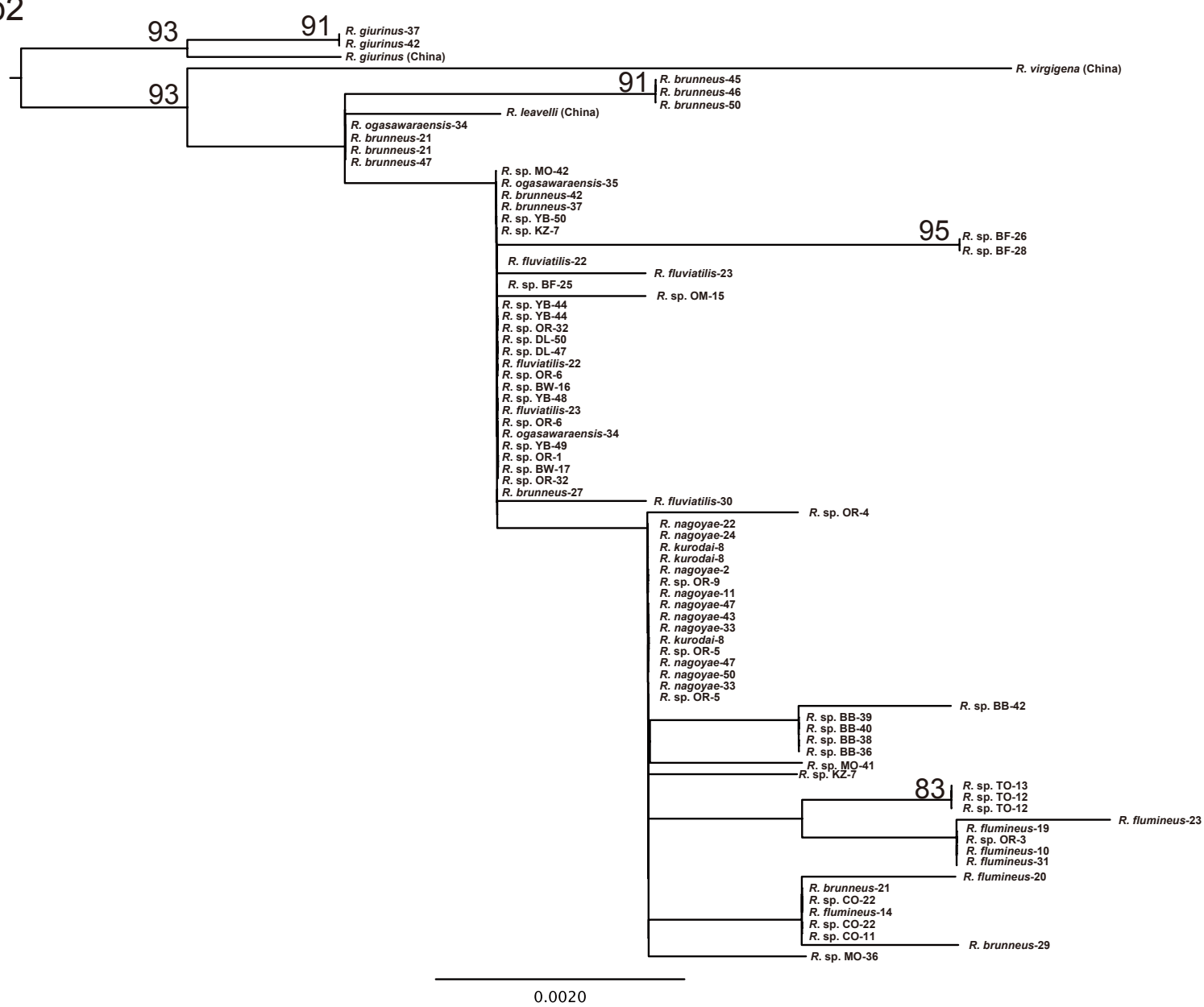

(f) EGR3

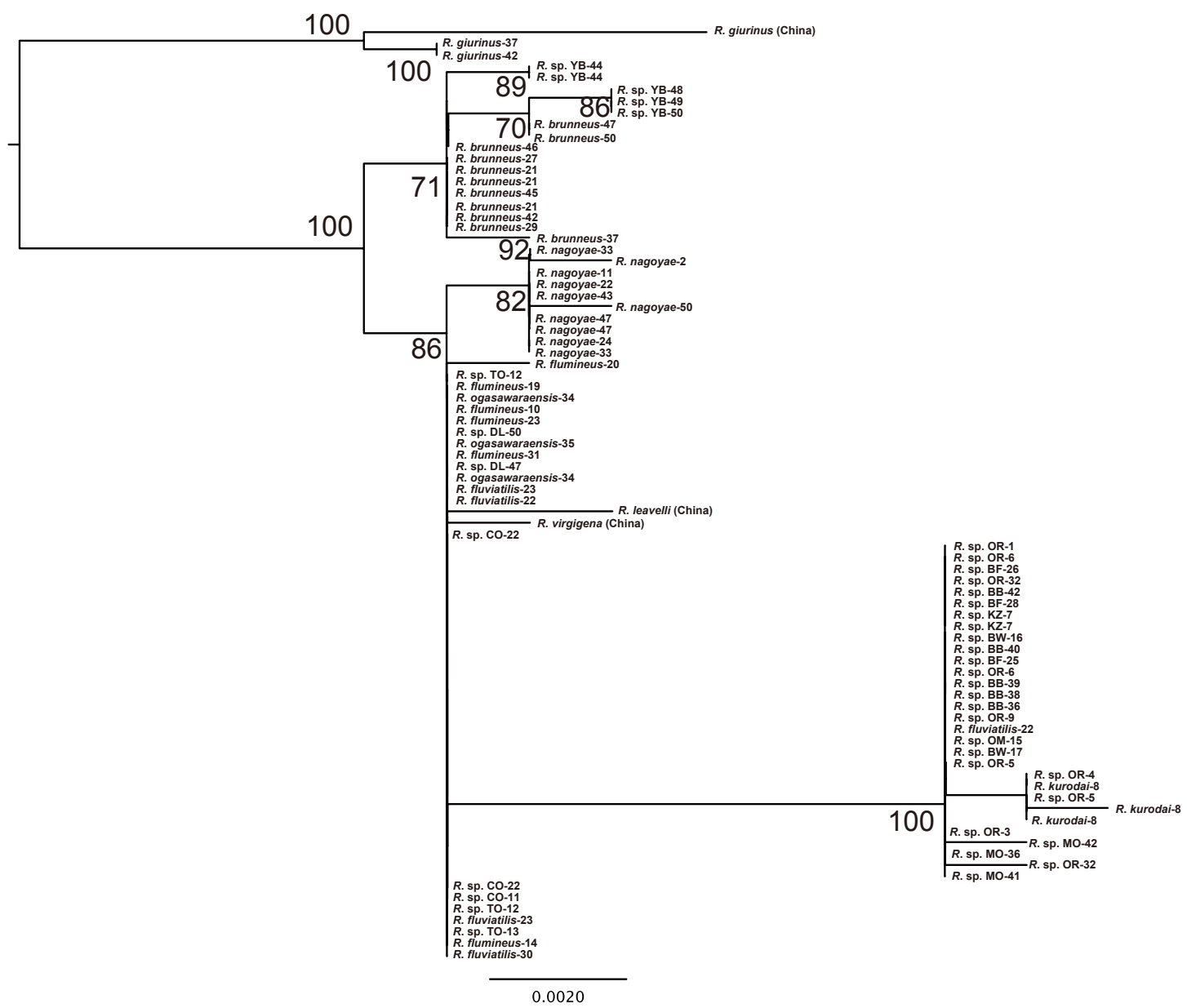

Fig. S2 Continued. 
Table S1.

Distribution and life history characteristics of Japanese Rhinogobius species.

\begin{tabular}{|c|c|c|c|c|c|c|}
\hline Scientific name & Japanese name & $\begin{array}{l}\text { Distribution in Japan (the mainland of } \\
\text { Japan/Ryukvu Archipelago) }\end{array}$ & Distribution outside Japan & Life history & Egg size & References \\
\hline Rhinogobius flumineus & Kawa-Yoshinobori & Yamanashi-Kyushu/ & $=$ & Fluvial & Large & Mizuno (1960) \\
\hline Rhinogobius sp. YB & Kibara-Yoshinobori & —/Ryukyu Archipelago & - & Fluvial & Middle & $\begin{array}{l}\text { Shinomiya et al. (2005); } \\
\text { Nishida (2001); Kon and }\end{array}$ \\
\hline Rhinogobius sp. BB & Aobara-Yoshinobori & —/North area of Okinawa Island & - & Fluvial & Middle & $\begin{array}{l}\text { Hirashima and Tachihara } \\
\text { (2000) Kato and Nishida } \\
\text { (1994); Nishida (2001) }\end{array}$ \\
\hline Rhinogobius sp. OM & Oumi-yoshinobori & Shiga, Lake Biwa/- & - & $\begin{array}{l}\text { Amphidromous } \\
\text { b }\end{array}$ & Small & $\begin{array}{l}\text { Maruyama et al. (2004); } \\
\text { Takahashi and Okazaki }\end{array}$ \\
\hline Rhinogobius sp. $\mathrm{OR}^{\mathrm{a}}$ & Tou-Yoshinobori & Hokkaido-Kyushu/_- & $=$ & "' Amphidromous & Small & $\begin{array}{l}\text { Akihito et al. (2002) } \\
\text { Tsunagawa and Arai (2008); }\end{array}$ \\
\hline Rhinogobius brunneus & Kuro-Yoshinobori & Chiba-Kyushu/Yakushima-Iriomote Island & - & Amphidromous & Small & $\begin{array}{l}\text { Kato and Nishida (1994); } \\
\text { Tamada (2005a) }\end{array}$ \\
\hline Rhinogobius fluviatilis & Oo-Yoshinobori & Honshu-Kyushu/_- & - & Amphidromous & Small & $\begin{array}{l}\text { Tsunagawa and Arai (2008); } \\
\text { Tamada (2001) }\end{array}$ \\
\hline Rhinogobius sp. CO & Ruri-Yoshinobori & Hokkaido-Kyushu/—- & Korea & Amphidromous & Small & $\begin{array}{l}\text { Tsunagawa and Arai (2008); } \\
\text { Tamada (2001) } \\
\text { Tamada (2001); Kato and }\end{array}$ \\
\hline Rhinogobius nagoyae & Shima-Yoshinobori & Mainlands/Ryukyu Archipelago & Korea, Taiwan, China & Amphidromous & Small & $\begin{array}{l}\text { Nishida (1994); Tsunagawa } \\
\text { and Arai (2008);Wu et al. }\end{array}$ \\
\hline Rhinogobius sp. MO & Aya-Yoshinobori & —/Amamioshima-Kume-jima Island & $=$ & Amphidromous & Small & Kondo et al. (2013) \\
\hline Rhinogobius sp. DL & Hira-Yoshinobori & —/Yakushima-Iriomote-jima Island & $=$ & '...'Amphidromous & no data & Akihito et al. (2013) \\
\hline Rhinogobius ogasawaraensis & Ogasawara-Yoshinobori & Bonin Islands & $=$ & Amphidromous & Small & Suzuki et al. (2011) \\
\hline Rhinogobius sp. BW & Biwa-Yoshinobori & Lake Biwa/- & $=$ & Lentic & Small & $\begin{array}{l}\text { Takahashi and Okazaki } \\
\text { Tsunagawa et al. (2010a); }\end{array}$ \\
\hline Rhinogobius sp. TO & Tokai-Yoshinobori & Aichi, Mie, Gifu/—- & - & Lentic & Small & $\begin{array}{l}\text { Tsujimoto (2008); Yamasaki } \\
\text { (personal observation) } \\
\text { Tsunagawa et al. (2010b); }\end{array}$ \\
\hline Rhinogobius sp. BF & Shimahire-Yoshinobori & Kinki and Setouchi district/—- & - & Lentic & Small & $\begin{array}{l}\text { Tsujimoto (2008); Tsujimoto } \\
\text { et al. (2003); Hirashima and } \\
\text { Nakamura (2014) }\end{array}$ \\
\hline Rhinogobius sp. KZ & Kazusa-yoshinobori & Chiba/- & $\div$ & no data & no data & Akihito et al. (2013) \\
\hline Rhinogobius kurodai & Kuroda-haze & Tokyo, Kanagawa, Shizuoka/—- & $=$ & ... no data & no data & Akihito et al. (2013) \\
\hline Rhinogobius giurinus & Gokurakuhaze & Mainlands/Ryukyu Archipelago & Korea, Taiwan, China & Amphidromous & Small & $\begin{array}{l}\text { Wu et al. (2008); Akihito et } \\
\text { al. (2013); Tamada (2005b) }\end{array}$ \\
\hline
\end{tabular}

${ }^{a}$ Akihito et al. (2013) newly separated six morphological species (Rhinogobius sp. OM, Rhinogobius sp. KZ, R. kurodai, Rhinogobius sp. BW, Rhinogobius sp. TO, Rhinogonius sp. BF) from Rhinogobius OR in Akihito et al.

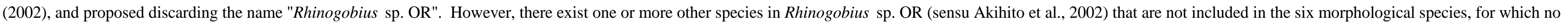
sicientific names/codes are given in Akihito et al. (2013). We hence use the name "Rhinogobius sp. OR" for the remaining species in the present paper.

${ }^{\mathrm{b}}$ Rhinogobius sp. OM mainly inhabits the middle to lower reaches of rivers flowing into Lake Biwa and its shore. It exhibits amphidromous life history using the lake instead of the ocean, and is treated as the amphidromous type.

References

Hirashima, K., Nakamura, K., 2014. Larval morphological changes and salinity tolerance of aquarium-held freshwater goby Rhinogobius sp. BF. Jpn. J. Ichthyol. 61, 53-57. (in Japanese with English abstract) Kon, T., Yoshino, T., 2003. Coloration and ontogenetic features of fluviatile species of Rhinogobius (Gobioidei: Gobiidae) in Amami-oshima Island, Ryukyu Island, Japan. Ichthyol. Res. 50, 109-116.

Maruyama, A., Yuma, M., Onoda, Y., 2004. Egg size variation between the fluvial-lacustrine and lacustrine types of s landlocked Rhinogobius goby in the Lake Biwa water system. Ichthyol. Res. 51 , 172-175. Island, Japan. Japan. J. Ichthyol. 52, 1-8. (in Japanese with English abstract) 
Tamada, K., 2005a. Clutch and Egg size in Rhinogobius sp. DA inhabiting small rivers, Japan. J. Ichthyol. 52, 17-20. (in Japanese with English abstract)

Tamada, K., 2005b. Egg and clutch sizes of a goby Rhinogobius giurinus in the Aizu River, Kii Peninsula, Japan. Ichthyol. Res. 52. 392-395.

243, 2421-243.

Wu H-L, Chen I-S., Zhong, J-S., 2008. Rhinogobius Gill, 1859. in: Wu, H-L., Zhong, J-S. (Eds.), Fauna Sinica Osteichthyes Perciformes (V) Gobioidei. Science Press, Beijing, China, pp. 568-635, 891-985.(in Chinese) 
Table S2

Accession and voucher numbers of samples used in this study.

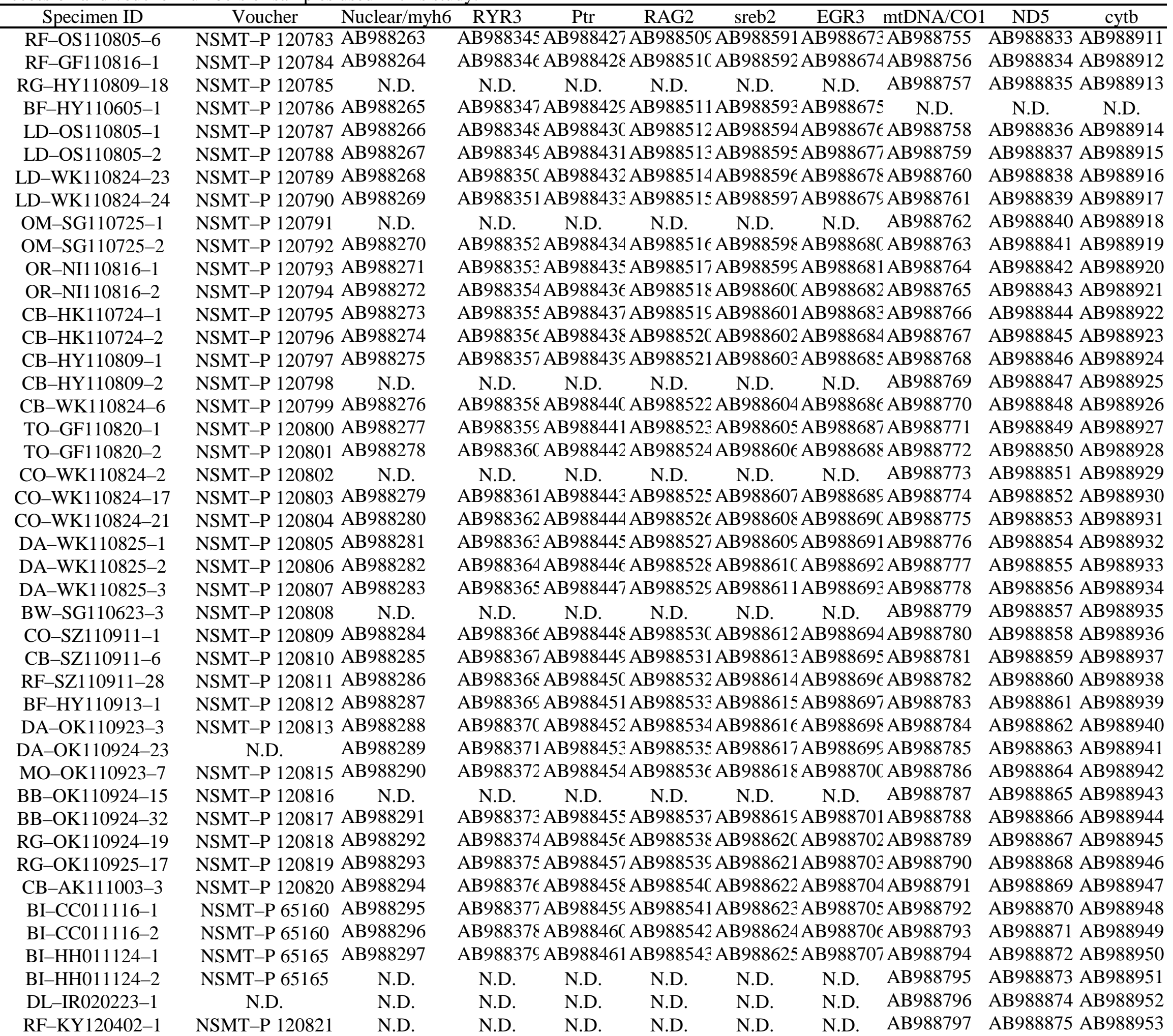

OR-HK110724-5 NSMT-P 120822 AB988298

OR-HK110724-6 NSMT-P 120823 AB988299

CB-IR120327-1 NSMT-P 120824 AB988300

DA-IR120327-2 NSMT-P 120825 AB988301

MO-OK111211-1

MO-OK111211-2

BB-OK120305-1

BB-OK120305-2

DL-IR120328-1

YB-OK111211-3

YB-OK111211-4

YB-IR120328-3

YB-IR120328-4

BF-OY110722-1

DA-SM120511-1

LD-SM120511-5

TO-GF120415-7

CB-OK110925-2

DA-IR120622-4

DA-IR120625-1

DA-IR120626-1

DL-IR120622-2

CB-IR120622-1

CB-IR120622-3

YB-PN120622-5

YB-KR120624-1

OR-FS091026-1

OR-FS091026-2

R.leavelli

AB98838C AB988462 AB988544 AB98862є AB98870ع AB988798 AB988381 AB98846? AB988545 AB988627 AB98870C N.D. AB988382 AB988464 AB98854€ AB98862\& AB98871C AB988799 AB98838? AB988465 AB988547 AB98862C AB988711 AB988800 AB988384 AB98846€ AB988548 AB98863C AB988712 AB988801

N.D. N.D. N.D. N.D. N.D. AB988802 AB988385 AB988467 AB98854C AB988631 AB988713 AB988803 AB98838€ AB988468 AB98855C AB988632 AB988714 N.D. AB988387 AB98846C AB988551 AB988632 AB988715 N.D. AB98838\& AB98847C AB988552 AB988634 AB98871€ AB988804 AB98838C AB988471 AB988553 AB988635 AB988717 AB988805

N.D. N.D. N.D. N.D. N.D. AB988806 AB98839C AB988472 AB988554 AB98863€ AB98871E AB988807 AB988391 AB988473 AB98855 AB988637 AB98871C AB988808 AB988392 AB988474 AB988556 AB988638 AB98872C AB988809 AB98839? AB988475 AB988557 AB98863 AB988721 AB988810 AB988394 AB98847€ AB988558 AB98864C AB988722 AB988811 AB988395 AB988477 AB98855 AB988641 AB98872? N.D. AB988396 AB988478 AB98856C AB988642 AB988724 AB988812 AB988397 AB98847C AB988561 AB988643 AB98872ㄷ AB988813 AB988398 AB98848C AB988562 AB988644 AB98872€ AB988814 AB98839C AB988481 AB98856? AB98864ᄃ AB988727 AB988815 AB98840C AB988482 AB988564 AB988646 AB98872\& AB988816 AB988401 AB988482 AB988565 AB988647 AB98872C N.D. AB988402 AB988484 AB98856€ AB988648 AB98873C AB988817 AB98840₹ AB98848` AB988567 AB98864C AB988731 AB988818 AB98840ᄃ AB988487 AB98856ऽ AB988651 AB98873 N.D. N.D. N.D. AB98840€ AB98848E AB98857C AB988652 AB988734 AB988820 AB988898 AB988976

N.D. N.D.

AB988877 AB988955

AB988878 AB988956 AB988879 AB988957 AB988880 AB988958 AB988881 AB988959 $\begin{array}{ll}\text { N.D. N.D. } & \text { N.D. }\end{array}$ AB988882 AB988960 AB988883 AB988961 AB988884 AB988962 AB988885 AB988963 AB988886 AB988964 AB988887 AB988965 AB988888 AB988966 AB988889 AB988967 N.D. N.D. AB988890 AB988968 AB988891 AB988969 AB988892 AB988970 AB988893 AB988971 AB988894 AB988972 N.D. N.D. AB988895 AB98 N.D. N.D. AB988321 N.D. AB988322 N.D. AB988323

NSMT-P 120835 AB988324 
R.virgigena RG-CH990405-1 OR-IW081011-2 OR-IW090528-1 OR-HO120408-1 RF-HI120512-1 RF-YN120714-1 OR-YN120714-5 RF-ME120905-1 RF-NR120930-1 DA-KW120730-1 KU-TK100705-1 KU-TK100705-2 KU-TK100705-3 BW-SG130523-1 BW-SG130601-1 BB-OK121111-1 BB-OK121111-4 BB-OK121111-5 MO-OK121111-3 KZ-CB100418-1 KZ-CB100418-2 KZ-CB100418-3 CB-OK130630-1 CB-OK130630-2
NSMT-P 120836 AB988325 NSMT-P 120837 AB988326 N.D. AB988327 NSMT-P 120838 AB988328 N.D. AB988329 N.D. AB988330 NSMT-P $120839 \quad$ N.D. NSMT-P 120840 AB988331 NSMT-P 120841 AB988332 NSMT-P 120842 AB988333 NSMT-P 120843 AB988334 NSMT-P 120844 AB988335 NSMT-P 120845 AB988336 NSMT-P 120846 AB988337 NSMT-P 120849 AB988338 NSMT-P 120850 AB988339 NSMT-P 120851 AB988340 NSMT-P $120852 \quad$ N.D. NSMT-P 120853 AB988341 NSMT-P 120854 AB988342 NSMT-P $120855 \quad$ N.D. NSMT-P 120856 AB988343 NSMT-P 120857 AB988344 NSMT-P $120860 \quad$ N.D. NSMT-P $120861 \quad$ N.D.
AB988407 AB98848C AB988571 AB988652 AB988735 AB988821 AB988899 AB988977 AB98840\& AB98849C AB988572 AB988654 AB988736 N.D. N.D. N.D. AB98840 AB988491 AB988573 AB988655 AB988737 N.D. N.D. N.D. AB98841C AB988492 AB988574 AB988656 AB988738 AB988822 AB988900 AB988978 AB988411 AB988492 AB988575 AB988657 AB98873С N.D. N.D. N.D. AB988412 AB988494 AB98857€ AB988658 AB98874C N.D. N.D. N.D.

N.D. N.D. N.D. N.D. N.D. AB988823 AB988901 AB988979 AB988413 AB988495 AB988577 AB98865ऽ AB988741 N.D. $\quad$ N.D. $\quad$ N.D. AB988414 AB988496 AB988578 AB98866C AB988742 N.D. N.D. N.D. AB988415 AB988497 AB98857C AB988661 AB988743 N.D. N.D. N.D. AB98841€ AB988498 AB98858C AB988662 AB988744 N.D. N.D. N.D. AB988417 AB98849C AB988581 AB988662 AB988745 AB988824 AB988902 AB988980 AB98841E AB98850C AB988582 AB988664 AB988746 AB988825 AB988903 AB988981 AB98841C AB988501 AB98858` AB988665 AB988747 N.D. N.D. N.D. AB98842C AB988502 AB988584 AB988666 AB988748 N.D. N.D. N.D. AB988421 AB98850₹ AB98858ᄃ AB988667 AB98874C AB988826 AB988904 AB988982 AB988422 AB988504 AB988586 AB988668 AB98875C N.D. N.D. N.D.

N.D. N.D. N.D. N.D. N.D. AB988827 AB988905 AB988983 AB988423 AB988505 AB988587 AB98866ऽ AB988751 N.D. N.D. N.D. AB988424 AB98850€ AB988588 AB98867C AB988752 N.D. N.D. N.D.

N.D. N.D. N.D. N.D. N.D. AB988828 AB988906 AB988984 AB988425 AB988507 AB98858C AB988671 AB988752 AB988829 AB988907 AB988985 AB98842€ AB988508 AB98859C AB988672 AB988754 AB988830 AB988908 AB988986 $\begin{array}{llll}\text { N.D. N.D. N.D. N.D. N.D. AB988831 AB988909 AB988987 } & \text { A }\end{array}$ $\begin{array}{llllll}\text { N.D. N.D. N.D. } & \text { N.D. } & \text { N.D. AB988832 AB988910 AB988988 }\end{array}$ 
Table S3.

Information of loci and primers used in this study

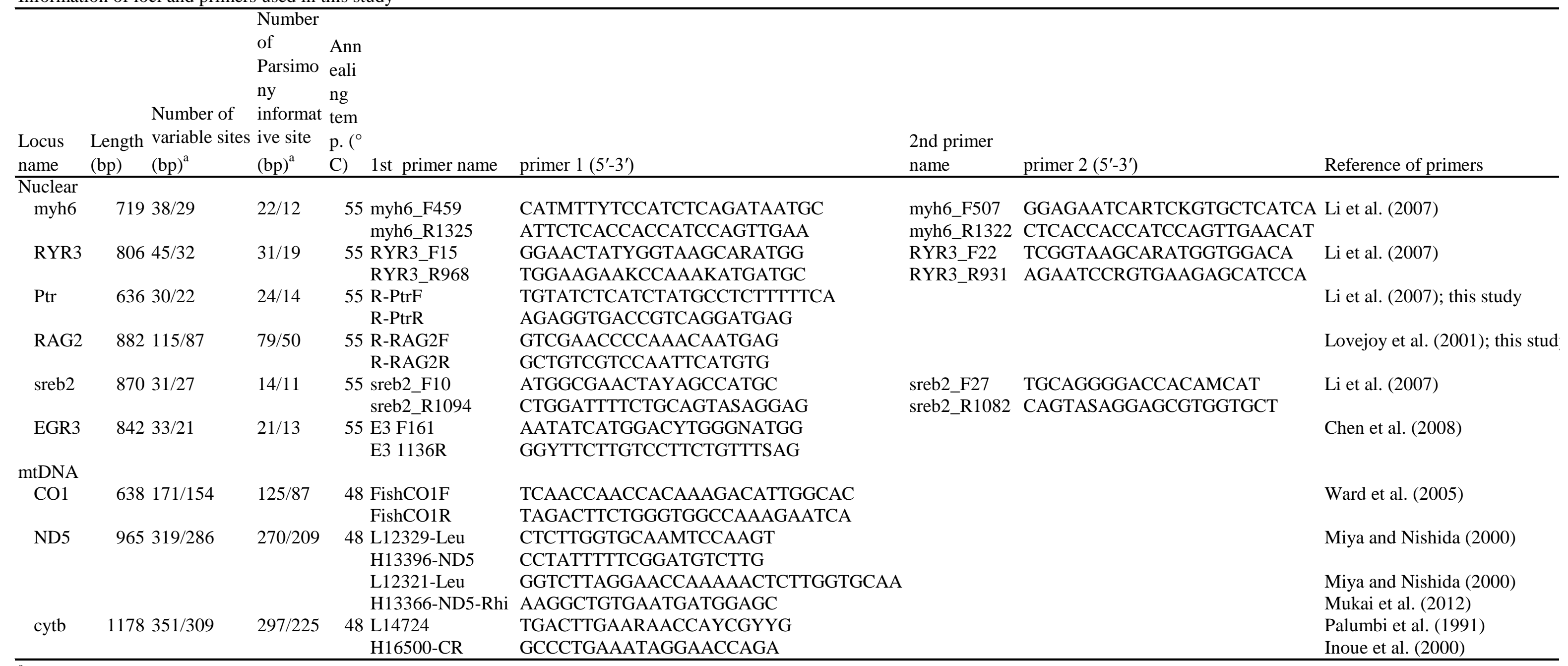

${ }^{a}$ With outgroup / without outgroup

Reference

Chen, W.J., Miya, M., Saitoh, K., Mayden, R.L., 2008. Phylogenetic utility of two existing and four novel nuclear gene loci in reconstructing tree of life of ray-finned fishes: The order Cypriniformes (Ostariophysi) as a case study. Gene 243, 125-134.

Inoue, J.G., Miya, M., Tsukamoto, K. Nishida, M. 2000. Complete mitochondrial DNA sequence of the Japanese sardine, Sardinops melanostictus. Fish. Sci. 66, 924-932.

Li, C., Orti, G., Zhang, G., Lu, G., 2007. A practical approach to phylogenomics: the phylogeny of ray-finned fish (Actinopterygii) as a case study. BMC Evol. Biol. 7, 44.

Lovejoy, N.R., Collette, R.B., 2001. Phylogenetic relationships of New World needlefishes (Teleosti: Belonidae) and the biogeography of transitions between marine and freshwater habitats. Copeia 2 ,

Miya, M., Nishida, M., 2000. Use of mitogenomic information in teleostean molecular phylogenetics: a tree-based exploration under the maximum-parsimony optimality criterion. Mol. Phylogenet. Fvnl 17 427-455

Palumbi, S., Martin, A., Romano, S., McMillian, W.O., Stice, L., Grabowski, G., 1991. The simple fool's guide to PCR. University of Hawaii, Honolulu.

Ward, R.D., Zemlak, T. S., Innes, B.H., Last, P.R., Hebert, P.D.N., 2005. DNA barcoding Australia’s fish species Phil. Trans. R. Soc. B 360, $1847-1857$. 
Table S4.

Models selected by Partitionfinder, using AIC for RAxML and BIC for MrBayes.

\begin{tabular}{|c|c|c|}
\hline & Subset partition & Best model \\
\hline \multicolumn{3}{|c|}{ RAxML/mtDNA } \\
\hline & 1 CO1-1st, CO1-2nd, ND5-1st, ND5-2nd, cytb-1st, cytb-2nd & $\mathrm{GTR}+\mathrm{I}+\mathrm{G}$ \\
\hline & 2 CO1-3rd, ND5-3rd, cytb-3rd & $\mathrm{GTR}+\mathrm{I}+\mathrm{G}$ \\
\hline \multicolumn{3}{|c|}{ MrBayes/mtDNA } \\
\hline & 1 CO1-2nd, ND5-2nd, cytb-2nd & GTR+I \\
\hline & 2 CO1-3rd, ND5-3rd, cytb-3rd & $\mathrm{GTR}+\mathrm{I}+\mathrm{G}$ \\
\hline & 3 CO1-1st, ND5-1st, cytb-1st & $\mathrm{K} 80+\mathrm{I}+\mathrm{G}$ \\
\hline \multicolumn{3}{|c|}{ RAxML/nuclear } \\
\hline & $\begin{array}{l}1 \text { myh6-1st, myh6-2nd, RYR3-1st, RYR3-3rd, Ptr-1st, Ptr-2nd, RAG2-2nd, RAG2-3rd, sreb2-1st, } \\
\text { sreb2-2nd, EGR3-1st, EGR3-2nd }\end{array}$ & $\mathrm{GTR}+\mathrm{I}+\mathrm{G}$ \\
\hline & 2 myh6-3rd, RYR3-2nd, Ptr-3rd, RAG2-1st, sreb2-3rd, EGR3-3rd & $\mathrm{GTR}+\mathrm{I}+\mathrm{G}$ \\
\hline \multicolumn{3}{|c|}{ MrBayes/nuclear } \\
\hline & 1 myh6-2nd, RYR3-1st & $\mathrm{F} 81+1$ \\
\hline & 2 myh6-3rd, RYR3-2nd, Ptr-3rd, sreb2-3rd, EGR3-3rd & $\mathrm{GTR}+\mathrm{I}+\mathrm{G}$ \\
\hline & 3 myh6-1st, RYR3-3rd, Ptr-1st, RAG2-2nd, RAG2-3rd, sreb2-1st & $\mathrm{HKY}+\mathrm{I}$ \\
\hline & 4 Ptr-2nd, sreb2-2nd & F81 \\
\hline & 5 RAG2-1st & $\mathrm{HKY}+\mathrm{I}$ \\
\hline & 6 EGR3-1st, EGR3-2nd & F81 \\
\hline
\end{tabular}


Table S5

Models for BEAST analysis selected by BIC implemented by jModelTest v 2.1.3. mtDNA

$\mathrm{CO} 1$

$\operatorname{TrN}+\mathrm{G}$

ND5

$\mathrm{TrN}+\mathrm{I}+\mathrm{G}$

cytb

GTR $+\mathrm{I}+\mathrm{G}$

nuclear DNA

Concatenated

$\mathrm{HKY}+\mathrm{I}+\mathrm{G}$ 
Table S6

Estimated parameters by state dependent diversification analysis under the MuSSE model. Character state codes (1-3) indicate amphidromous, lentic, and fluvial in life history analysis, and small, middle , large in egg size analysis respectively. These models estimated speciation $(\lambda)$, extinction $(\mu)$, and transition rates $(q)$.

\section{Model}

\section{Full}

Equal $\lambda$

Equal $\mu$

Equal q

Equal $\lambda$ and $\mu$

Equal $\lambda$ and $q$ (reversal transition rates are equal)

Equal $\mu$ and $q$ (reversal transition rates are equal)

Equal q (all transition rates are equal)

Equal $\lambda, \mu, q$ (reversal transition rates are equal)

Equal $\lambda$ and $q$ (all transition ratse are equal)

Equal $\mu$ and $q$ (all transition rates are equal)

Equal $\lambda, \mu, q$ (all transition rates are equal)

\section{Egg size}

Full

Equal $\lambda$

Equal $\mu$

Equal $\mathrm{q}$

Equal $\lambda$ and $\mu$

Equal $\lambda$ and $q$ (reversal transition rates are equal)

Equal $\mu$ and $q$ (reversal transition rates are equal)

Equal q (all transition rates are equal)

Equal $\lambda, \mu, \mathrm{q}$ (reversal transition rates are equal)

Equal $\lambda$ and $q$ (all transition rates are equal)

Equal $\mu$ and $q$ (all transition rates are equal)

Equal $\lambda, \mu, q$ (all transition rates are equal)

$7 \quad 109.980 .439$ -

$5106.710 .462-$

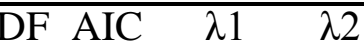

$12118.18 \quad 0.485$

$\begin{array}{lll}10 & 115.21 & 0.447\end{array}$

$\begin{array}{lll}10 & 114.18 & 0.485\end{array}$

$\begin{array}{lll}9 & 112.77 & 0.492\end{array}$

8111.290 .429 -

$\begin{array}{llll}7 & 108.77 & 0.492\end{array}$

$\begin{array}{lll}7 & 109.53 & 0.512\end{array}$

5106.020 .429 -

$\begin{array}{lll}5 & 105.80 & 0.496\end{array}$

3103.060 .429 -

0.3790 .145$$
\text { - } 2.72 \mathrm{E}-119.36 \mathrm{E}-10
$$

0.3790 .145 6.29E-07 -

0.3540 .140

$$
\text { - 5.19E-09 - }
$$

0.3540 .140 8.86E-09 -

0.3590 .204 6.87E-06

- 3.75E-08

0.3040 .198 3.88E-08 -

$\mu 3$

q12 q21

q13

q31

q23

q32

$12 \quad 106.22 \quad 0.511$

$\begin{array}{llll}10 & 102.86 & 0.438 & \text { - }\end{array}$

1.58E-08

$\begin{array}{llll}10 & 102.22 & 0.511 & 1.75\end{array}$

6 0.335 4.91E-06 1.97E-11 5.54E-06 0.2125

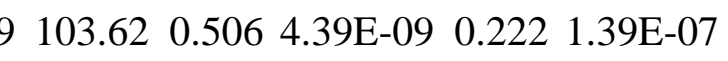

$\begin{array}{llll}8 & 98.88 & 0.429 & -\end{array} \quad-\quad 9.15 \mathrm{E}-07$ -

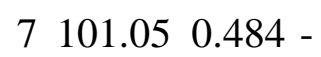

- $\quad 6.76 \mathrm{E}-07$

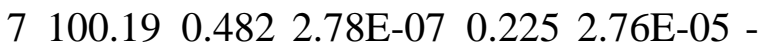

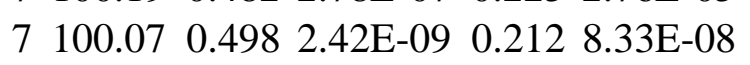

$598.17 \quad 0.429-$

$597.50 \quad 0.476-\quad-\quad 3.70 \mathrm{E}-08$

$\begin{array}{llllll}5 & 96.41 & 0.481 & 1.06 \mathrm{E}-05 & 0.211 & 2.90 \mathrm{E}-07\end{array}$

$\begin{array}{llll}3 & 94.45 & 0.429-\quad & -\end{array}$
- 4.32E-09

- $\quad 2.70 \mathrm{E}-08-$

\begin{abstract}
3.4
-
-
\end{abstract}
$0.189-$

0.1890 .0

0.363 1.34E-05 0.1274 -

0.0567 -

$0.4440 .1490 .1249-$

0.1249 -
$0.1099-$

0.0744 3.67E-06

\subsection{19E-06}

0.0744 1.50E-05

$0.1035-$

0.0845 7.67E-08

0.1065 -

$0.1035-$

0.1057 -

$$
\text { - }
$$$$
0.0983 \text { - }
$$

1.085 5.12E-11

$2.2986 .15 \mathrm{E}-07$

1.085 5.04E-07

-

0.2125

0.592 1.42E-06 0.1372 -

0.0661 -

0.3955

2.304 5.66E-07

0.334 3.21E-09 3.58E-06

0.311 7.26E-08 5.95E-08

0.334 1.91E-09 1.07E-06

$$
5.19 \mathrm{E}-07-
$$

$1.023 \quad 0.3300 .1470-$

$0.0783-$

0.348 2.15E-09 7.88E-10

$0.429 \quad 0.1320 .0929-$

$0.0695-$

7.07E-09-

3.55E-05 -

$0.855 \quad 0.3870 .1022$ -

0.0651 -

1.28E-07 - 